\title{
Renal proximal tubular NEMO plays a critical role in ischemic acute kidney injury
}

\author{
Sang Jun Han, ${ }^{1}$ Ryan M. Williams, ${ }^{2}$ Mihwa Kim, ${ }^{1}$ Daniel A. Heller, ${ }^{3}$ Vivette D'Agati, ${ }^{4}$ \\ Marc Schmidt-Supprian, ${ }^{5}$ and $\mathrm{H}$. Thomas Lee ${ }^{1}$ \\ 'Department of Anesthesiology, College of Physicians and Surgeons of Columbia University, New York, New York, \\ USA. ${ }^{2}$ Department of Biomedical Engineering, City College of New York, New York, New York, USA. ${ }^{3}$ Department of \\ Molecular Pharmacology \& Chemistry, Memorial Sloan Kettering Cancer Center, New York, New York, USA. ${ }^{4}$ Department \\ of Pathology, College of Physicians and Surgeons of Columbia University, New York, New York, USA. ${ }^{5}$ Institute of \\ Experimental Hematology, School of Medicine, Technical University Munich, Munich, Germany.
}

\begin{abstract}
We determined that renal proximal tubular (PT) NF-кB essential modulator (NEMO) plays a direct and critical role in ischemic acute kidney injury (AKI) using mice lacking renal PT NEMO and by targeted renal PT NEMO inhibition with mesoscale nanoparticle-encapsulated NEMO binding peptide (NBP MNP). We subjected renal PT NEMO-deficient mice, WT mice, and C57BL/6 mice to sham surgery or 30 minutes of renal ischemia and reperfusion (IR). C57BL/6 mice received NBP MNP or empty MNP before renal IR injury. Mice treated with NBP MNP and mice deficient in renal PT NEMO were protected against ischemic AKI, having decreased renal tubular necrosis, inflammation, and apoptosis compared with control MNP-treated or WT mice, respectively. Recombinant peptidylarginine deiminase type 4 (rPAD4) targeted kidney PT NEMO to exacerbate ischemic AKI in that exogenous rPAD4 exacerbated renal IR injury in WT mice but not in renal PT NEMO-deficient mice. Furthermore, rPAD4 upregulated proinflammatory cytokine mRNA and NF-KB activation in freshly isolated renal proximal tubules from WT mice but not from PT NEMOdeficient mice. Taken together, our studies suggest that renal PT NEMO plays a critical role in ischemic AKI by promoting renal tubular inflammation, apoptosis, and necrosis.
\end{abstract}

Conflict of interest: DAH is a cofounder and officer with equity interest in LipidSense Inc.; Nirova BioSense Inc.; and Goldilocks Therapeutics Inc. DAH is a member of the scientific advisory board of Concarlo Holdings, LLC and Nanorobotics Inc. RMW is a scientific advisor with equity interest in Goldilocks Therapeutics Inc.

Copyright: (c) 2020, Han et al. This is an open access article published under the terms of the Creative Commons Attribution 4.0 International License.

Submitted: April 17, 2020

Accepted: September 3, 2020

Published: September 17, 2020.

Reference information: JCI Insight. 2020;5(19):e139246

https://doi.org/10.1172/jci.

insight.139246.

\section{Introduction}

Acute kidney injury (AKI) is a major clinical problem, but there is no effective therapy (1-3). Renal ischemia and reperfusion (IR) injury is a leading cause of AKI, as patients undergoing cardiac, vascular, or liver transplant surgical procedures have approximately a $50 \%-80 \%$ chance of developing ischemic AKI $(4,5)$. Renal IR results in rapid proximal tubular necrosis followed by tubular inflammatory response with leukocyte influx (6-8). Indeed, upregulation of renal tubular proinflammatory cytokines and chemokines causes influx of inflammatory leukocytes into the renal parenchyma and exacerbates ischemic AKI (9-11). Therefore, regulating the renal tubular inflammatory process after renal IR could potentially lead to therapy to protect against ischemic AKI.

We previously showed that renal tubular peptidylarginine deiminase type 4 (PAD4), a calcium-dependent enzyme that catalyzes the conversion of peptidylarginine residues to peptidylcitrulline, is rapidly upregulated after renal IR injury $(12,13)$. Furthermore, we demonstrated that kidney PAD4 plays a critical role in ischemic $\mathrm{AKI}$ in that PAD4 inhibitors or genetic deletion of PAD4 protected against ischemic AKI (12). We also showed that recombinant PAD4 (rPAD4) worsens ischemic AKI by promoting renal tubular inflammation via NF- $\mathrm{kB}$ activation, renal tubular cytokine generation, and neutrophil infiltration (12). Renal tubular PAD4 induction is mediated by P2X7 receptor activation secondary to release of ATP from necrotic renal cells (14). Finally, we showed that renal tubular PAD4 promotes a proinflammatory arm of the NF- $\mathrm{NB}$ activation pathway by selectively citrullinating IKK $\gamma(\mathrm{NF}-\kappa \mathrm{B}$ essential modulator [NEMO] a regulatory subunit of the IKK complex) over IKK $\alpha$ or IKK $\beta$ subtypes. NEMO inhibition with NEMO binding peptide (NBP) attenuated renal tubular NF- $\mathrm{B}$ activation, proinflammatory gene induction, renal tubular neutrophil infiltration, and ischemic AKI in mice (15).

However, since NEMO is present in every cell type in the kidney as well as extrarenal organs, it remains to be determined whether renal PT NEMO plays a critical role in generating ischemic AKI by 
PAD4-mediated citrullination. Furthermore, since NEMO plays important and diverse physiological roles in almost all cell types, systemic NEMO inhibition is not feasible as a therapeutic option to treat ischemic AKI. Therefore, in this study, we tested whether renal PT NEMO plays a critical role in ischemic AKI using 2 distinct mechanistic approaches. We generated and subjected mice with renal PT NEMO deficiency to renal IR injury. We also used a potentially novel mesoscale nanoparticle-mediated (MNP-mediated) drug delivery approach to selectively deliver NBP to renal proximal tubular cells to protect against ischemic AKI.

\section{Results}

Confirmation of renal PT NEMO deletion in NEMO ${ }^{\text {t/fl}}$ PEPCK-Cre mice. NEMO mRNA and protein expression in renal proximal tubules from $\mathrm{NEMO}^{\mathrm{f} / \mathrm{fl}}$ phosphoenolpyruvate carboxykinase promoter-Cre (PEPCK-Cre) mice was decreased by more than $99.99 \%$ and more than $96 \%$, respectively, compared with $\mathrm{NEMO}^{\mathrm{f} / \mathrm{fl}}$ mice (Figure 1, A and B). However, NEMO mRNA expression in isolated bone marrow cells, intestine, and spleen was equivalent between $\mathrm{NEMO}^{\mathrm{f} / \mathrm{fl}} \mathrm{PEPCK}-\mathrm{Cre}$ mice and $\mathrm{NEMO}^{\mathrm{f} / \mathrm{fl}}$ mice. Whole kidney and liver NEMO mRNA expressions were approximately $32 \%$ lower in $\mathrm{NEMO}^{\mathrm{f} / \mathrm{fl}} \mathrm{PEPCK}-\mathrm{Cre}$ mice compared with $\mathrm{NEMO}^{\mathrm{f} / \mathrm{fl}}$ mice (Figure 1A). These findings are consistent with renal proximal tubular and periportal hepatocyte expression of PEPCK-Cre recombinase $(16,17)$.

Generation of MNPs containing NBP and confirmation of renal tubular MNP delivery. Lyophilized MNPs containing NBP exhibited a mean hydrodynamic diameter of $315.4 \pm 4.9 \mathrm{~nm}$ and a polydispersity index (PDI) of $0.29 \pm 0.03$. These particles encapsulated $431 \mathrm{ng}$ NBP/1 mg MNP for an encapsulation efficiency of $89 \%$. Empty control MNPs were $332.0 \pm 7.6 \mathrm{~nm}$ in diameter with a PDI of $0.30 \pm 0.04$. The renal proximal tubular distribution pattern for the MNPs was confirmed by colocalization of PEG staining with phytohemagglutinin (PHA) lectin staining in mice injected with $38 \mathrm{mg} / \mathrm{kg} \mathrm{MNP}$ (Figure 1C, representative of 3 experiments). PEG staining did not colocalize with the collecting duct-specific AQP-2 staining, and PEG staining was not detected in other tissues, including the lung, spleen, and liver. These results demonstrated preferential localization of MNPs in renal proximal tubular cells.

Kidney PT NEMO deletion or selective tubular delivery of NBP encapsulated in MNP protects against ischemic $A K I$ in mice. Plasma creatinine and blood urea nitrogen (BUN) values were similar between $\mathrm{NEMO}^{\mathrm{f} / \mathrm{fl}}$ mice and renal PT NEMO-null mice subjected to a sham operation (Figure 2A). NEMO ${ }^{\mathrm{f} / \mathrm{fl}}$ mice subjected to renal IR had significantly higher plasma creatinine and BUN as well as kidney neutrophil gelatinase-associated lipocalin $(\mathrm{NGAL})$ mRNA $(N=5)$ compared with sham-operated $\mathrm{NEMO}^{\mathrm{f} / \mathrm{fl}}$ mice $(N=3)$. In preliminary studies, we determined that PEPCK-Cre mice subjected to renal IR had a similar degree of renal injury when compared with $\mathrm{NEMO}^{\mathrm{f} / \mathrm{fl}}$ mice (data not shown). We found here that renal PT NEMO-null mice subjected to renal IR were protected against ischemic AKI compared with control $\mathrm{NEMO}^{\mathrm{f} / \mathrm{fl}}$ mice, as demonstrated by reduced plasma creatinine and BUN as well as kidney NGAL mRNA expression $(N=5)$.

Since liver NEMO mRNA expressions were approximately $32 \%$ lower in NEMO ${ }^{\mathrm{f} / \mathrm{fl}} \mathrm{PEPCK}-\mathrm{Cre}$ mice compared with $\mathrm{NEMO}^{\mathrm{f} / \mathrm{fl}}$ mice given that periportal hepatocytes express PEPCK-Cre recombinase (16, 17), we determined whether there are differences in hepatic injury after ischemic AKI between $\mathrm{NEMO}^{\mathrm{f} / \mathrm{fl}}$ PEPCK-Cre mice and $\mathrm{NEMO}^{\mathrm{f} / \mathrm{fl}}$ mice. There were no differences in alanine aminotransferase (ALT) levels between sham-operated $\mathrm{NEMO}^{\mathrm{f} / \mathrm{fl}}$ mice $(18 \pm 10 \mathrm{U} / \mathrm{L}, N=3)$ and $\mathrm{NEMO}^{\mathrm{f} / \mathrm{fl}}$ PEPCK-Cre mice $(27 \pm 6$ $\mathrm{U} / \mathrm{L}, N=3)$. Moreover, there were no differences in ALT levels between $\mathrm{NEMO}^{\mathrm{f} / \mathrm{fl}}$ mice $(146 \pm 19 \mathrm{U} / \mathrm{L}$, $N=5)$ and $\mathrm{NEMO}^{\mathrm{f} / \mathrm{fl}} \mathrm{PEPCK}-\mathrm{Cre}$ mice $(145 \pm 23 \mathrm{U} / \mathrm{L}, N=5)$ subjected to renal IR. In addition, histological liver injuries were similar after renal IR between $\mathrm{NEMO}^{\mathrm{f} / \mathrm{fl}}$ mice and $\mathrm{NEMO}^{\mathrm{f} / \mathrm{fl}} \mathrm{PEPCK}-\mathrm{Cre}$ mice (Supplemental Figure 1; supplemental material available online with this article; https://doi.org/10.1172/ jci.insight.139246DS1).

Plasma creatinine and BUN values were similar between sham-operated C57BL/6 mice injected with empty control MNPs and $38 \mathrm{mg} / \mathrm{kg}$ NBP encapsulated in MNPs (NBP MNP, $N=3$, Figure 2B). Mice treated with control MNPs and subjected to renal IR had significantly higher plasma creatinine and BUN as well as kidney NGAL mRNA $(N=5)$ compared with sham-operated mice $(N=3)$. We showed here that mice treated with 19 or $38 \mathrm{mg} / \mathrm{kg}$ NBP MNP 6 hours before renal ischemia or mice treated with $38 \mathrm{mg} / \mathrm{kg}$ NBP MNP 15 minutes after reperfusion were protected against ischemic AKI compared with control MNP-treated mice, as demonstrated by reduced plasma creatinine and BUN as well as kidney NGAL mRNA expression $(N=5-7)$.

Kidney PT NEMO deletion or selective tubular delivery of NBP MNP reduces renal tubular necrosis after ischemic $A K I$. Figure 3A shows representative kidney $\mathrm{H} \& \mathrm{E}$ images of $\mathrm{NEMO}^{\mathrm{f} / \mathrm{fl}}$ mice and renal $\mathrm{PT} \mathrm{NEMO}-$ null 
A

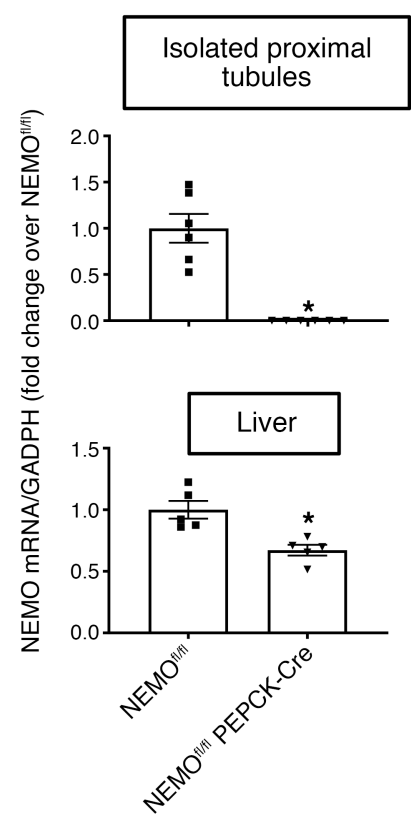

C
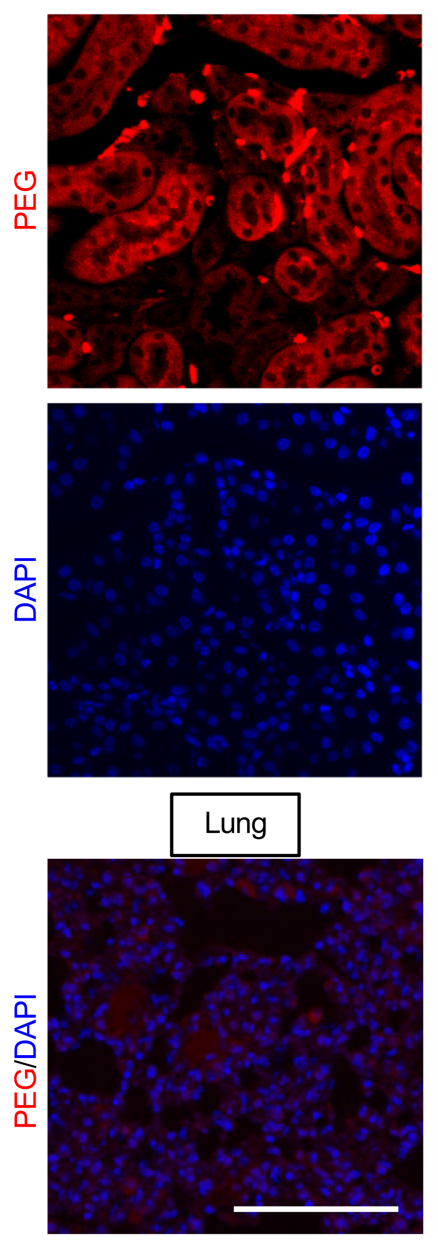
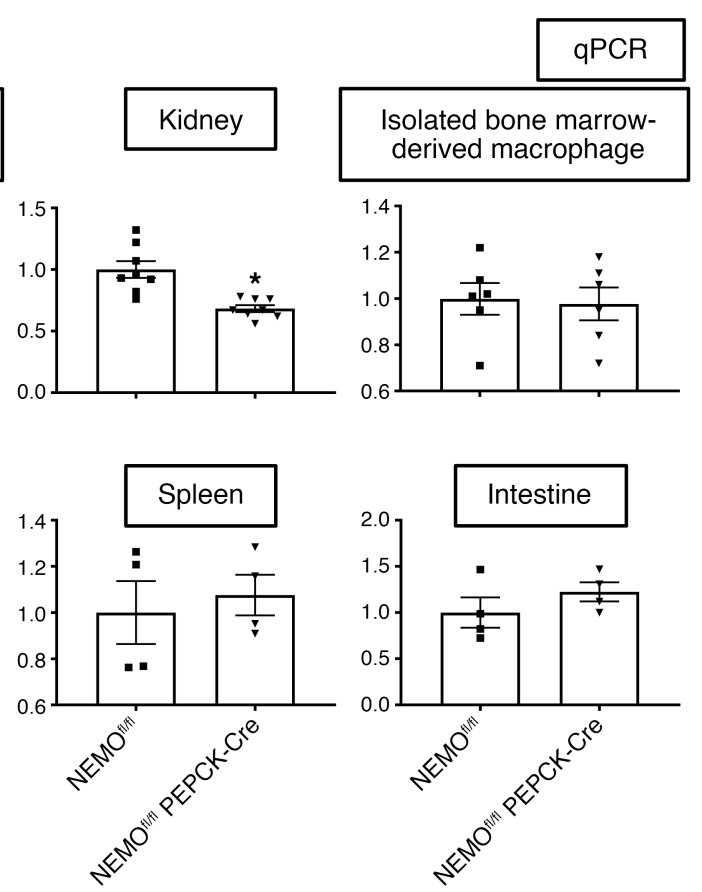

$38 \mathrm{mg} / \mathrm{kg}$ NBP MNP injection and $30 \mathrm{~min}$ RIR
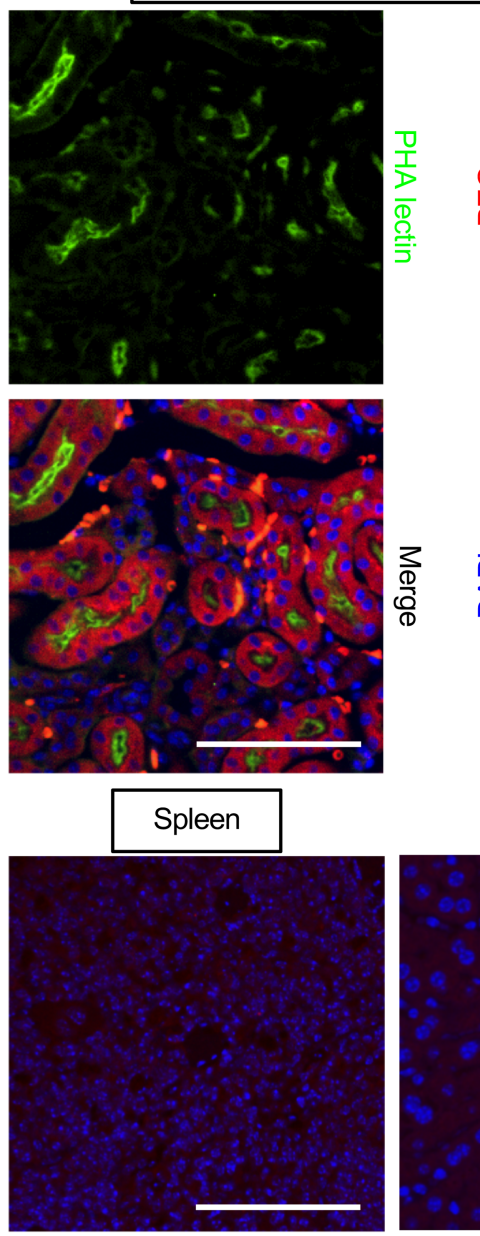

밈

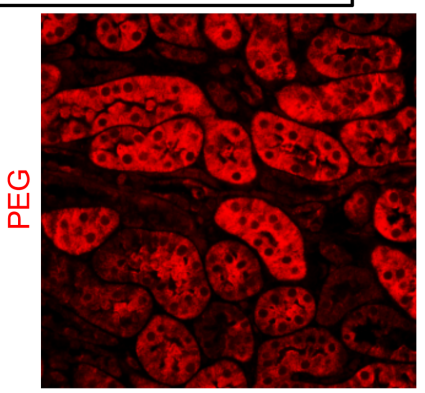

B

Isolated proximal tubules
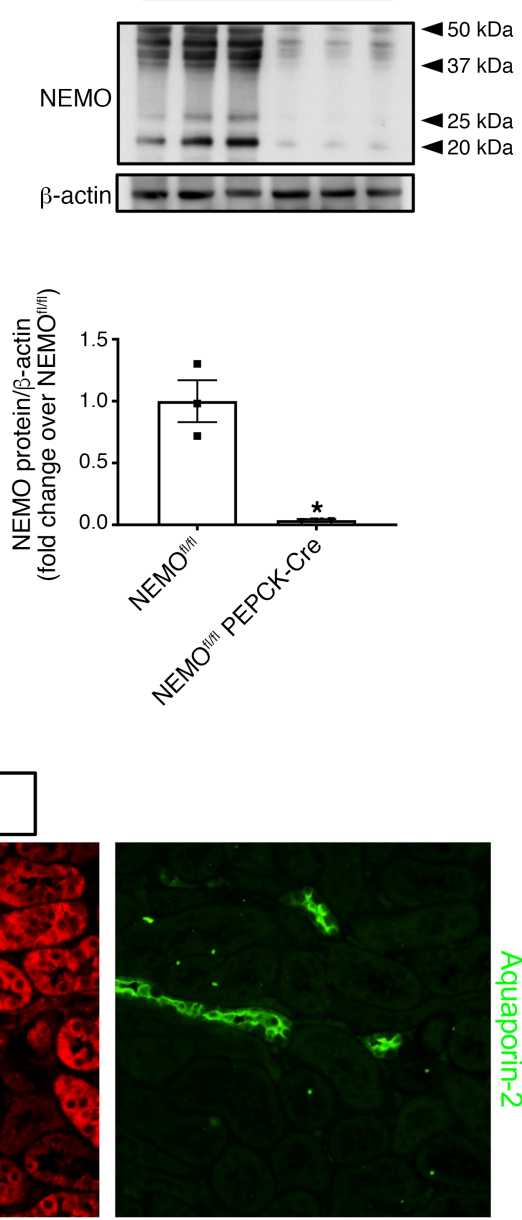

產
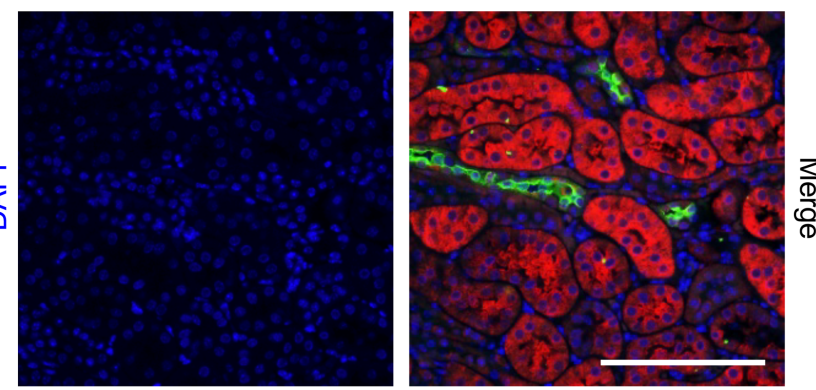

Liver

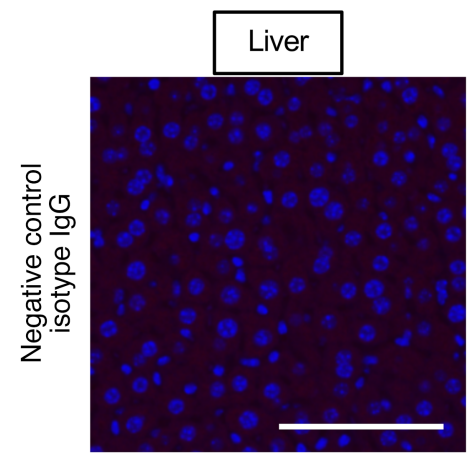


Figure 1. Confirmation of renal proximal tubule cell NEMO deletion in proximal tubule cell NEMO-null mice. (A) NEMO mRNA normalized to GAPDH from qRT-PCR reactions in isolated proximal tubule cells, bone marrow-derived macrophages, whole kidney, liver, spleen, and small intestine of WT

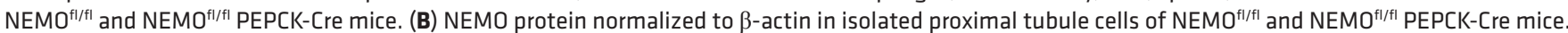
The bands below approximately $50 \mathrm{kDA}$ predicted molecular weight of NEMO may represent truncated forms, varying glycosylation products, and cleaved fragments. For statistical analysis, Student's $t$ test was used to detect significant changes. ${ }^{*} P<0.05$ versus NEMO ${ }^{f / f f}$ mice $(N=3-8)$. Error bars represent 1 SEM. (C) Confirmation of renal proximal tubule cell-specific MNP delivery. Mouse kidney sections stained with anti-PEG antibody to detect MNP localization and PHA-lectin to mark renal proximal tubule cells or with anti-aquaporin-2 antibody to mark renal collecting ducts and counterstained with DAP to visualize cell nuclei. Mice were injected with $38 \mathrm{mg} / \mathrm{kg}$ NBP MNP or with vehicle control 6 hours before renal IR injury. Renal proximal tubular distribution pattern for PEG was confirmed by colocalization of PEG antibody staining and PHA lectin staining in MNP-injected mice $(\times 200$ original magnification images shown, representative of 3 experiments). However, PEG staining was not detected in the lung, spleen, or liver ( $\times 200$ original magnification images shown, representative of 3 experiments). Scale bar: $50 \mu \mathrm{m}$.

mice subjected to sham surgery or 30 minutes of renal IR and 24 hours of reperfusion (original magnification, $\times 200, N=5$ ). $\mathrm{NEMO}^{\mathrm{f} / \mathrm{fl}}$ mice subjected to renal IR showed severe tubular necrosis and proteinaceous casts as well as increased tubular dilatation and congestion. In contrast, renal PT NEMO-null mice had decreased renal tubular necrosis, congestion, and cast formation compared with $\mathrm{NEMO}^{\mathrm{f} / \mathrm{fl}}$ mice subjected to renal IR. Kidneys from renal PT NEMO-null mice had significantly reduced renal tubular injury scores compared with control MNP-injected mice after IR (Figure 3B).

Figure 3C shows representative kidney H\&E images of control MNP-injected or $38 \mathrm{mg} / \mathrm{kg}$ NBP MNP-injected mice subjected to sham surgery or 30 minutes of renal IR and 24 hours of reperfusion (original magnification, $\times 200, N=5$ ). Control MNP-injected mice subjected to renal IR showed severe tubular necrosis and proteinaceous casts as well as increased tubular dilatation and congestion. Treatment with $38 \mathrm{mg} / \mathrm{kg}$ NBP MNP 6 hours before renal ischemia decreased renal tubular necrosis, congestion, and cast formation compared with the control MNP-injected mice subjected to renal IR. Kidneys from NBP MNPinjected mice had significantly reduced renal tubular injury scores compared with control MNP-injected mice after IR (Figure 3D).

Kidney PT NEMO deletion or selective tubular delivery of NBP MNP attenuates kidney apoptosis in mice after ischemic AKI. Figure 4A shows representative TUNEL-stained images indicative of renal apoptosis and counts of TUNEL-positive kidney cells (Figure 4B) from NEMO ${ }^{\mathrm{f} / \mathrm{fl}}$ mice and renal PT NEMO-null mice subjected to sham surgery $(N=3)$ or to renal IR $(N=5$, original magnification, $\times 200)$. We detected many positive TUNEL (fragmented DNA) cells, suggestive of renal tubular apoptosis in the kidneys from $\mathrm{NEMO}^{\mathrm{f} / \mathrm{fl}}$ mice subjected to renal IR injury. TUNEL-positive kidney cell counts were significantly reduced in renal PT NEMO-null mice subjected to renal IR injury.

Figure 4C shows representative TUNEL-stained images indicative of renal apoptosis and counts of TUNEL-positive kidney cells (Figure 4D) from control MNP-injected and $38 \mathrm{mg} / \mathrm{kg} \mathrm{NBP} \mathrm{MNP}-$ injected mice subjected to sham surgery $(N=3)$ or to renal IR $(N=5$, original magnification, $\times 200)$. We detected many positive TUNEL (fragmented DNA) cells, suggestive of renal tubular apoptosis in the kidneys from control MNP-injected mice subjected to renal IR injury. TUNEL-positive kidney cell counts were significantly reduced in NBP MNP-injected mice compared with control MNP-injected mice after IR.

Kidney PT NEMO deletion or selective tubular delivery of NBP MNPs reduces kidney neutrophil infiltration after ischemic $A K I$. Figure 5A shows representative IHC images and counts of infiltrating kidney neutrophils in the kidneys (Figure 5B) of $\mathrm{NEMO}^{\mathrm{fl} / \mathrm{fl}}$ mice and renal PT NEMO-null mice subjected to sham surgery $(N=$ 3 ) or renal IR $(N=5$, original magnification, $\times 200)$. Kidney neutrophil infiltration increased significantly in $\mathrm{NEMO}^{\mathrm{fl} / \mathrm{fl}}$ mice subjected to renal IR. Neutrophil infiltration was significantly reduced in renal PT NEMOnull mice subjected to renal IR injury.

Figure 5C shows representative IHC image counts of infiltrating kidney neutrophils in the kidneys (Figure 5D) of control MNP-injected mice and $38 \mathrm{mg} / \mathrm{kg}$ NBP MNP-injected mice subjected to sham surgery $(N=3)$ or renal IR $(N=5$, original magnification, $\times 200)$. Kidney neutrophil infiltration was significantly higher in control MNP-injected mice subjected to renal IR. NBP MNP treatment significantly attenuated kidney neutrophil infiltration after renal IR compared with NBP MNP-injected mice.

Kidney PT NEMO deletion or selective tubular delivery of NBP MNPs downregulates proinflammatory chemokine and cytokine induction and renal tubular NF- $\kappa B$ activation after ischemic AKI. Figure 6A shows fold increases in proinflammatory mRNAs normalized to GAPDH for each indicated mRNA in the kidneys of $\mathrm{NEMO}^{\mathrm{f} / \mathrm{fl}}$ mice and renal PT NEMO-null mice subjected to sham surgery $(N=3)$ or renal $\operatorname{IR}(N=5)$. Figure $6 \mathrm{C}$ shows fold increases in proinflammatory mRNAs normalized to GAPDH for each indicated mRNA in the kidneys of control MNP-injected mice and $38 \mathrm{mg} / \mathrm{kg}$ NBP MNP-injected mice subjected 
A
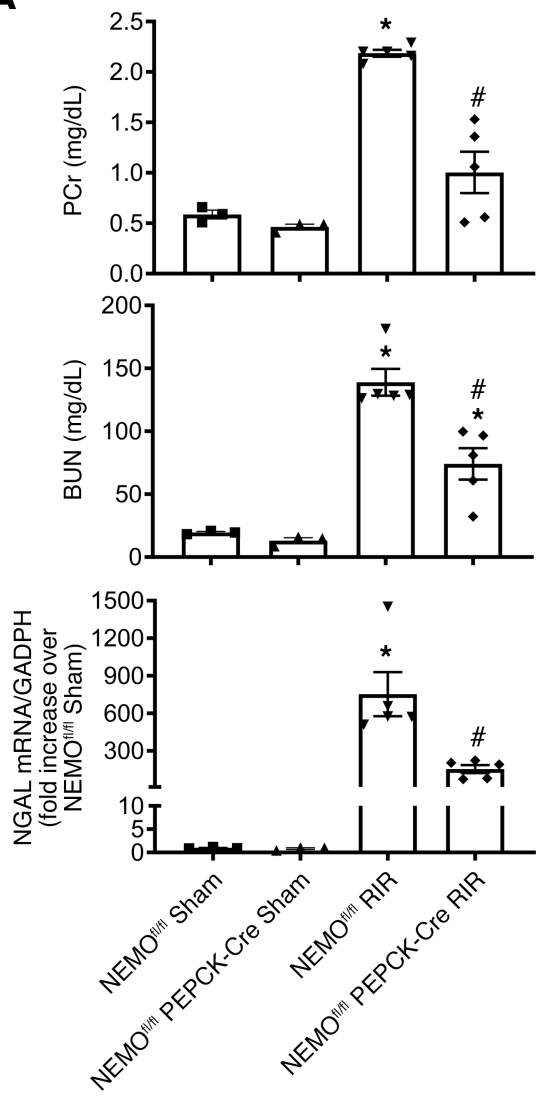

B
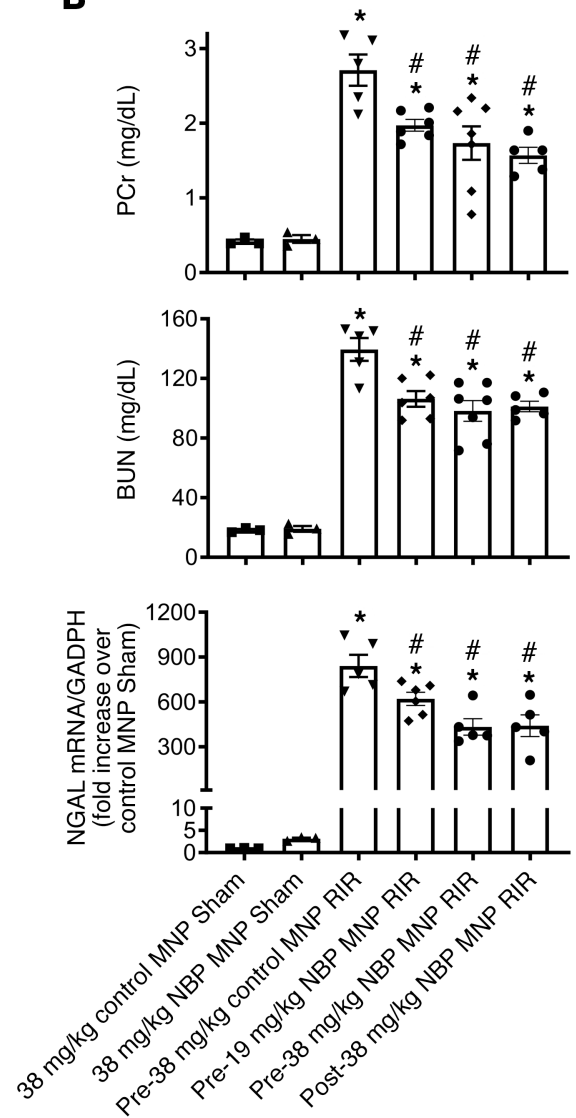

Figure 2. Kidney PT NEMO deletion or selective tubular delivery of NBP MNP protects against ischemic AKI in mice. (A) NEMO ${ }^{f / f l}$ WT mice or renal PT NEMO-deficient (NEMO fl/fl PEPCK-Cre) mice were subjected to sham surgery $(N=3)$ or to 30 minutes renal IR $(N=5)$. (B) Separate cohorts of C57BL/6 mice were injected with control MNP or with 19 or 38 $\mathrm{mg} / \mathrm{kg}$ NBP encapsulated in MNPs (NBP MNP) 6 hours before sham surgery $(N=3)$ or 30 minutes renal ischemia (IR, $N$ = 5-7). Some mice were injected with $38 \mathrm{mg} / \mathrm{kg}$ NBP MNP 15 minutes after reperfusion $(I R, N=5)$. Twenty-four hours later, plasma BUN and creatinine as well as kidney NCAL mRNA were measured. For statistical analysis, 1-way ANOVA plus Tukey's post hoc multiple-comparisons test was used to detect significant changes. ${ }^{*} P<0.05$ versus WT mice or control MNP-injected mice subjected to sham surgery. ${ }^{\#}<0.05$ versus WT mice or control MNP-injected mice subjected to renal IR. Error bars represent 1 SEM.

to sham surgery $(N=3)$ or renal IR $(N=5)$. Ischemic AKI increased all proinflammatory genes measured in $\mathrm{NEMO}^{\mathrm{A} / \mathrm{fl}}$ control mice or control MNP-injected mice. Consistent with the renal protective role of NEMO inhibition or deletion via reduction of neutrophil- and macrophage-attracting chemokines, we showed that macrophage inflammatory protein-2 (MIP-2) and monocyte chemoattractive protein-1 (MCP-1) mRNA expressions as well as plasma MIP-2 and MCP-1 protein levels (Figure 6, B and D) were significantly attenuated in renal PT NEMO-null mice or NBP MNP-injected mice. Moreover, IL-6, TNF- $\alpha$, and keratinocyte chemoattractant (KC) induction were attenuated in NBP MNP-injected mice or mice deficient in renal PT NEMO. Finally, renal IR significantly increased expressions of

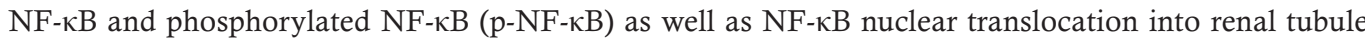
cells. Kidney PT NEMO deletion or selective tubular delivery of NBP MNP treatment attenuated these increases in NF- $\mathrm{kB}$ and $\mathrm{p}-\mathrm{NF}-\mathrm{\kappa B}$ expression (Figure 7 and Figure 8).

PAD4-mediated exacerbation of renal injury, apoptosis, and inflammation are attenuated in renal PT NEMO-deficient mice. We previously demonstrated that $\mathrm{PAD} 4$ treatment exacerbated ischemic AKI in mice $(12,13)$. To determine whether human $\mathrm{PAD} 4$ enters kidney and renal proximal tubular cells, mice were treated with $10 \mu \mathrm{g}$ rPAD4. We determined that rPAD4 treatment increased human PAD4 protein expression in both 
Sham surgery or 30 min renal ischemia and $24 \mathrm{~h}$ reperfusion
H\&E staining
A
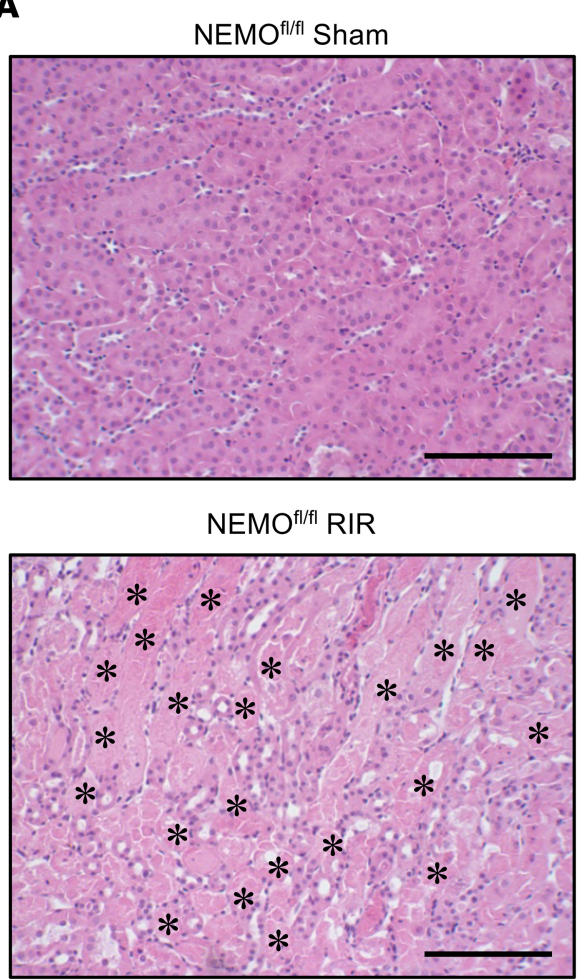

C

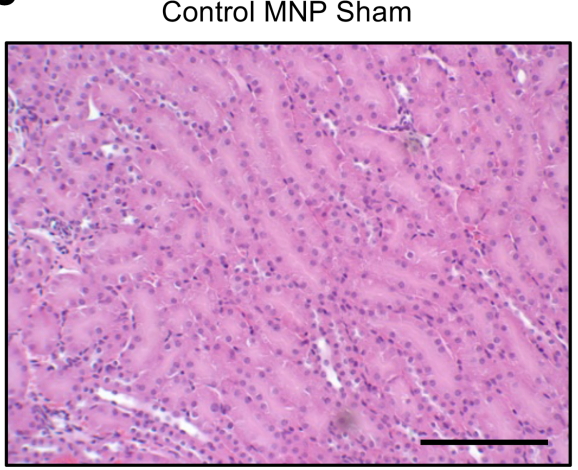

Control MNP RIR

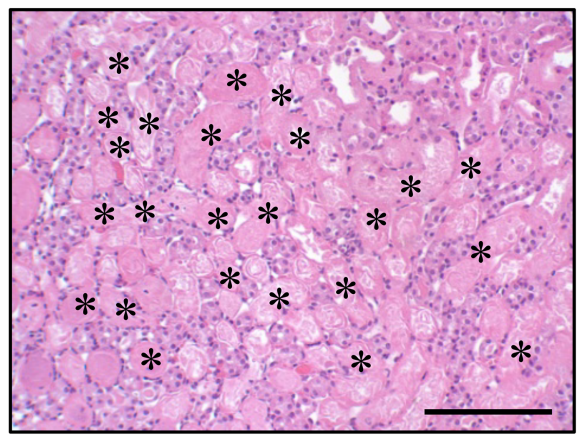

NEMO ${ }^{\text {fl/fl }}$ PEPCK-Cre Sham
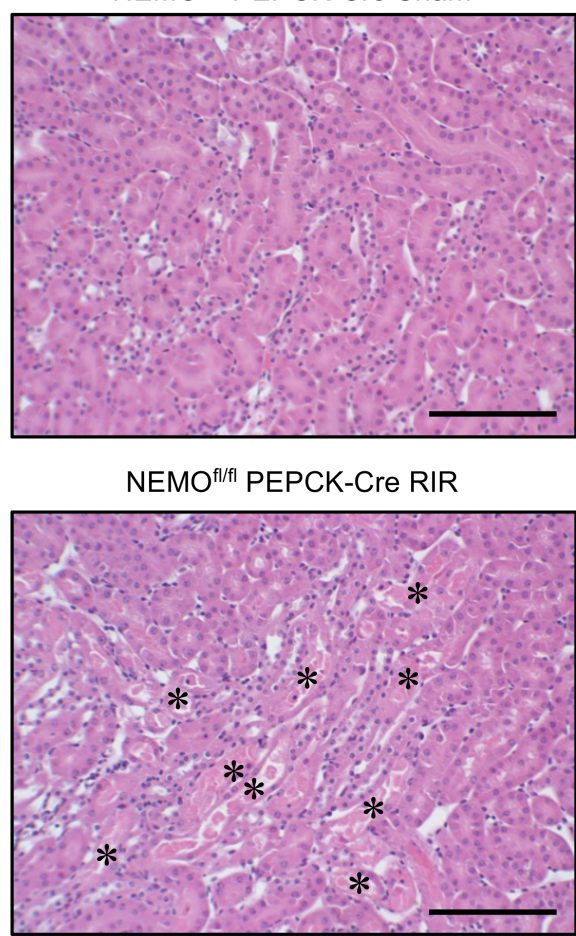

NBP MNP Sham

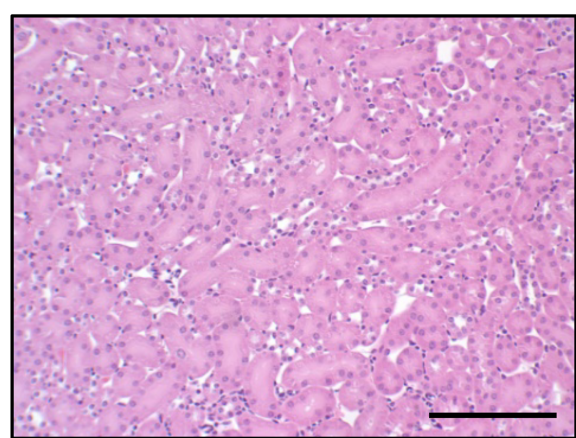

NBP MNP RIR

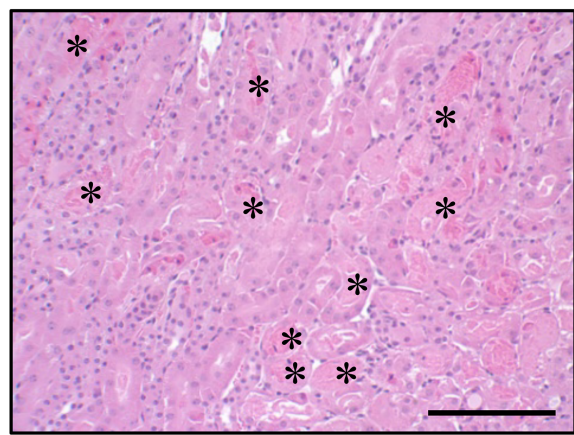

B

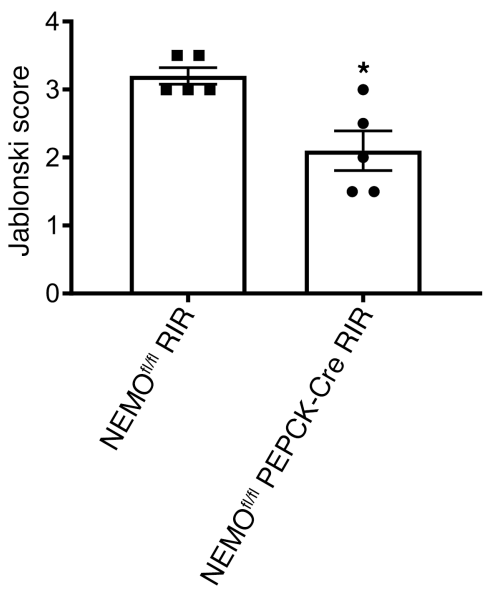

D

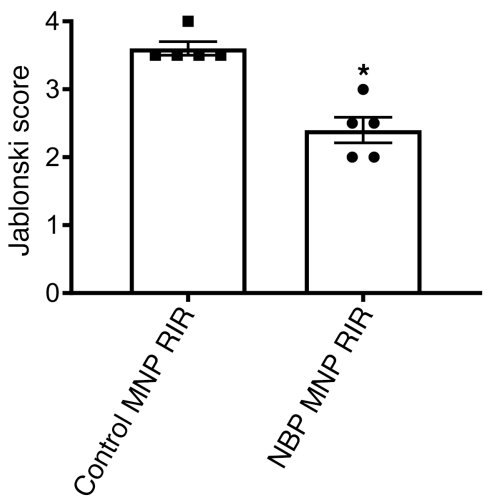

Figure 3. Kidney PT NEMO deletion or selective tubular delivery of NBP MNP reduces renal tubular necrosis after ischemic AKI. Representative H\&E images ( $\times 200$ original magnification, $\mathbf{A}$ and $\mathbf{C}$ ) and Jablonski renal injury scores assessing the degree of renal tubular necrosis (scale: 0-4, B and D) of kidneys of mice subjected to sham surgery or to 30 minutes renal ischemia and 24 hours reperfusion ( $\times 200$ original magnification). (A and B) NEMO ${ }^{\mathrm{fl} / \mathrm{fl}}$ WT mice or renal PT NEMO-deficient mice subjected to sham surgery or renal IR $(N=5)$. (C and D) C57BL/6 mice injected with control MNP or with 19 or $38 \mathrm{mg} / \mathrm{kg}$ NBP MNP 6 hours before sham surgery or renal IR ( $N$ $=5)$. Severe tubular necrosis and proteinaceous casts $\left(^{*}\right)$ are indicated in $\mathrm{H} \& \mathrm{E}$ images. Scale bar: $200 \mu \mathrm{m} .{ }^{*} P<0.05$ versus WT mice or control MNP-injected mice subjected to renal IR. Error bars represent 1 SEM. For statistical analysis, the Mann-Whitney nonparametric test was used to detect significant changes. 
Sham surgery or 30 min renal ischemia and $24 \mathrm{~h}$ reperfusion
TUNEL

staining
A

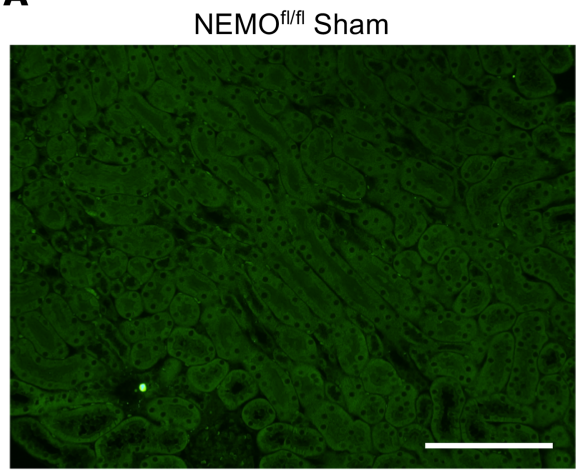

$N E M O f / f \mid R I R$

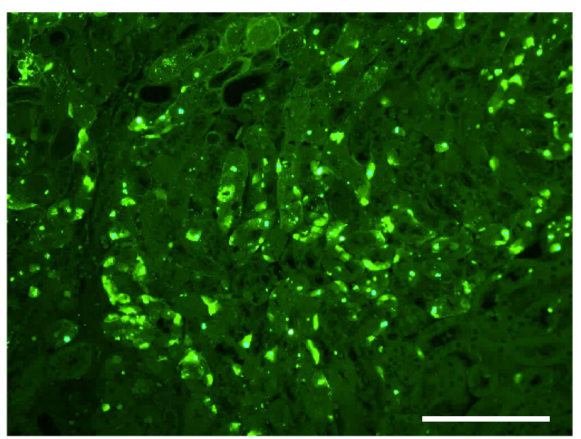

C

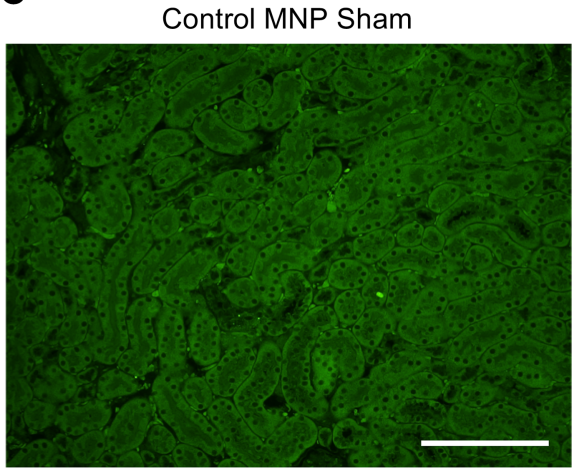

Control MNP RIR

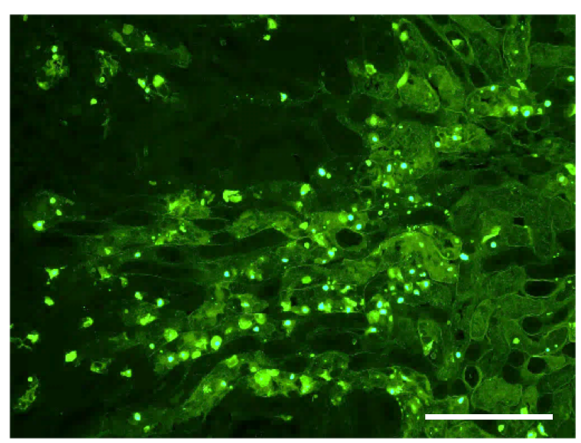

NEMOfl/fl PEPCK-Cre Sham

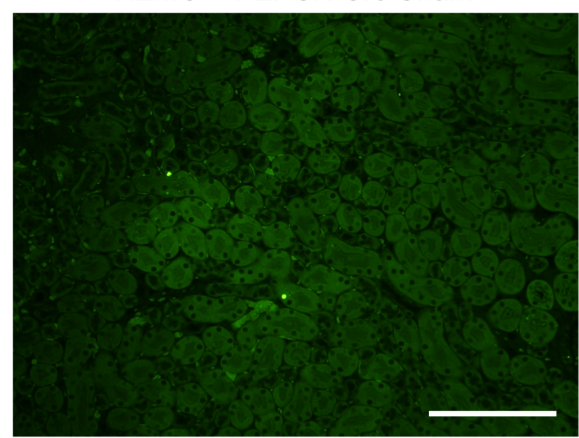

NEMO ${ }^{f / f l}$ PEPCK-Cre RIR

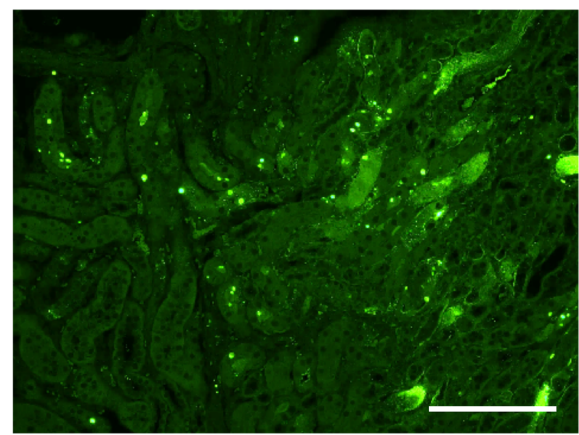

NBP MNP Sham

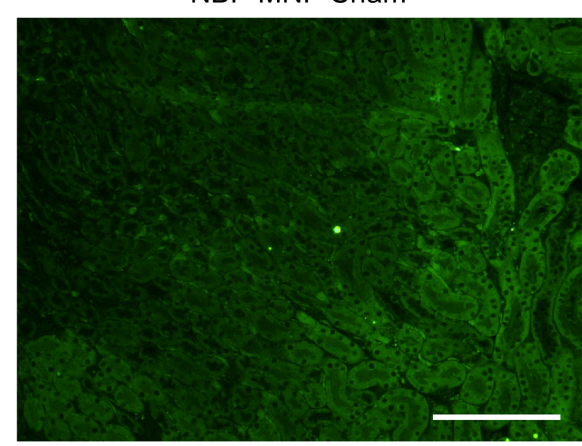

NBP MNP RIR

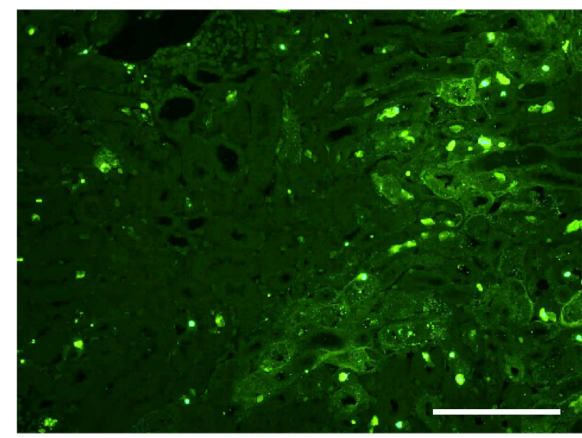

B

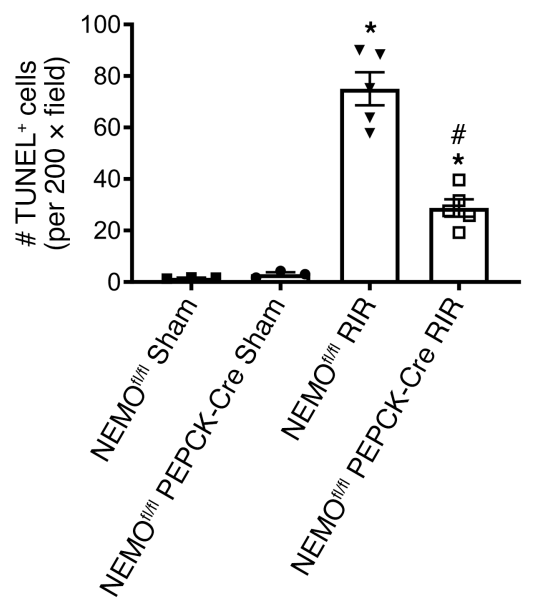

D

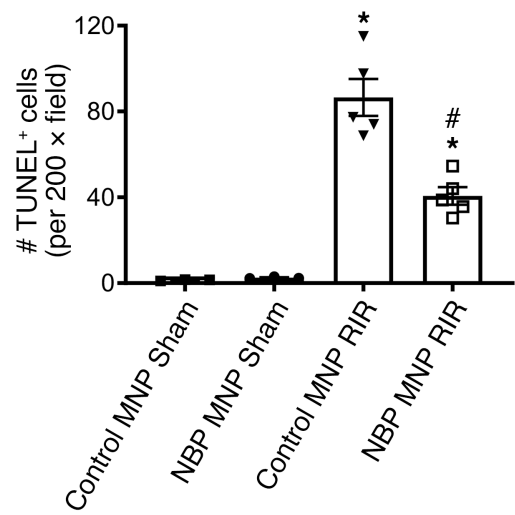

Figure 4. Kidney PT NEMO deletion or selective tubular delivery of NBP MNP attenuates kidney apoptosis after ischemic AKI. Representative images of TUNEL staining ( $\mathbf{A}$ and $\mathbf{C}$ ) indicative of renal tubular apoptosis and counts of TUNEL-positive kidney cells ( $B$ and $\mathbf{D}$ ) in the kidneys of mice subjected to sham surgery $(N=3)$ or to 30 minutes renal ischemia and 24 hours reperfusion $(N=$ $5, \times 200$ original magnification). (A and $\mathbf{B}) \mathrm{NEMO}^{\mathrm{fl} / \mathrm{fl}}$ WT mice or renal PT NEMO-deficient mice subjected to sham surgery or renal IR. (C and D) C57BL/6 mice injected with control MNP or with $38 \mathrm{mg} / \mathrm{kg}$ NBP MNP 6 hours before sham surgery $(N=3)$ or renal IR $(N=5)$. Scale bar: $200 \mu \mathrm{m}$. For statistical analysis, 1-way ANOVA plus Tukey's post hoc multiple-comparisons test was used to detect significant changes. ${ }^{*} P<0.05$ versus WT mice or control MNP-injected mice subjected to sham surgery. ${ }^{\#} P<0.05$ versus WT mice or control MNP-injected mice subjected to renal IR. Error bars represent 1 SEM. 
Sham surgery or 30 min renal ischemia and $24 \mathrm{~h}$ reperfusion
Ly6G IHC

staining
A
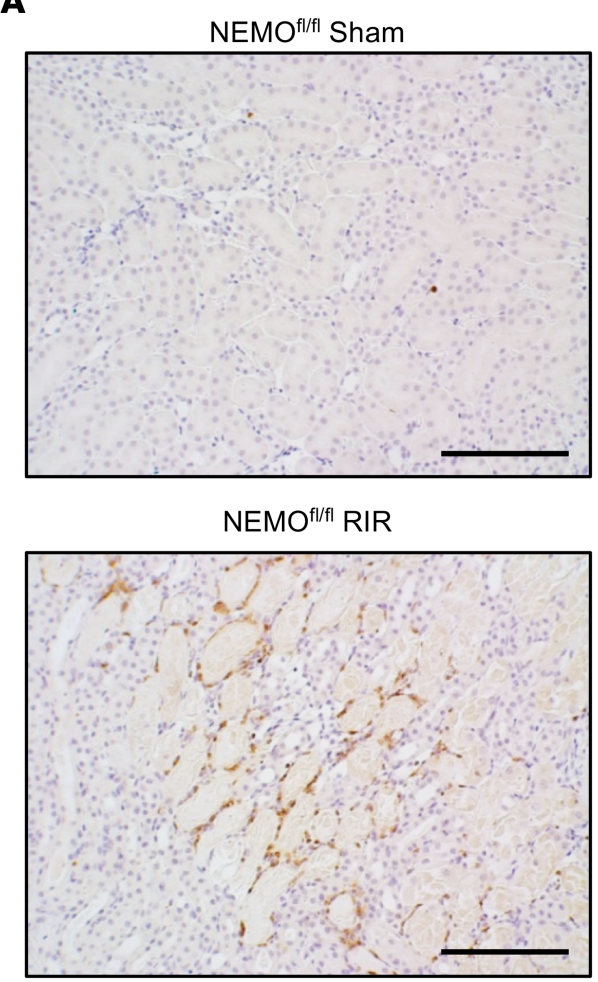

C
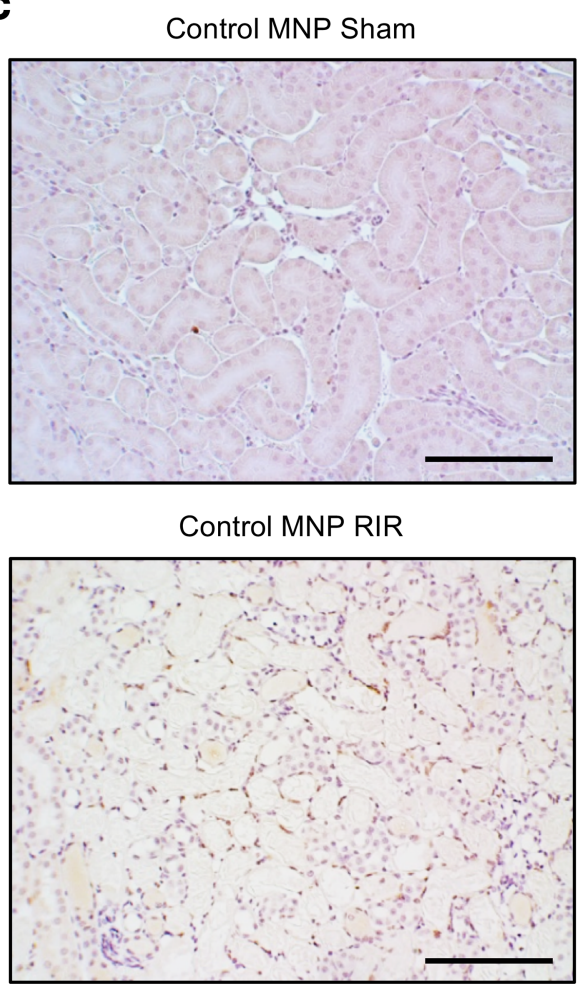

NEMO ${ }^{\text {fl/fl }}$ PEPCK-Cre Sham

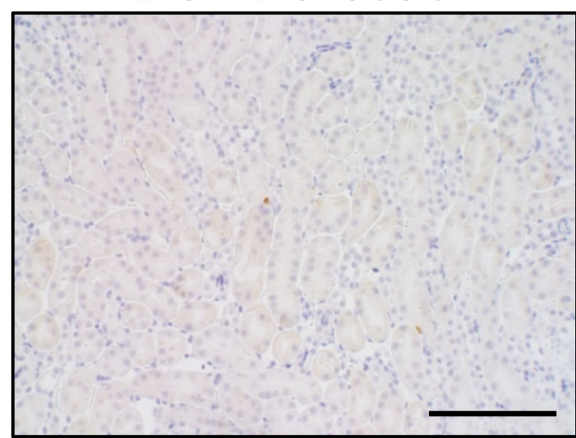

NEMO ${ }^{\text {flfl }}$ PEPCK-Cre RIR

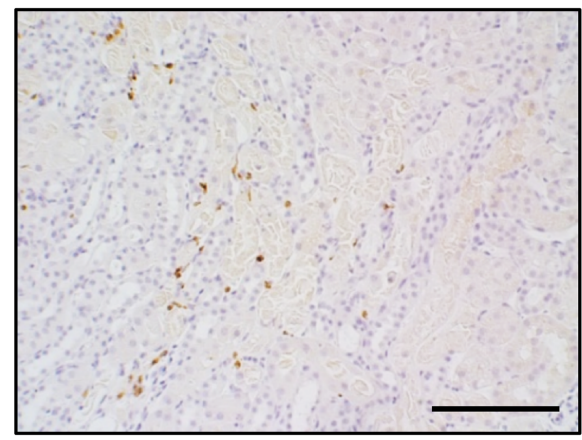

NBP MNP Sham

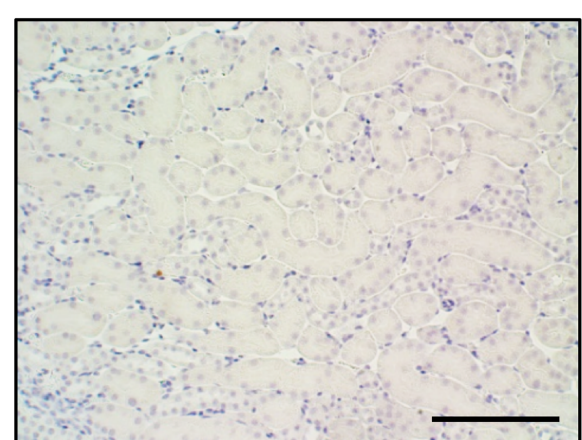

NBP MNP RIR

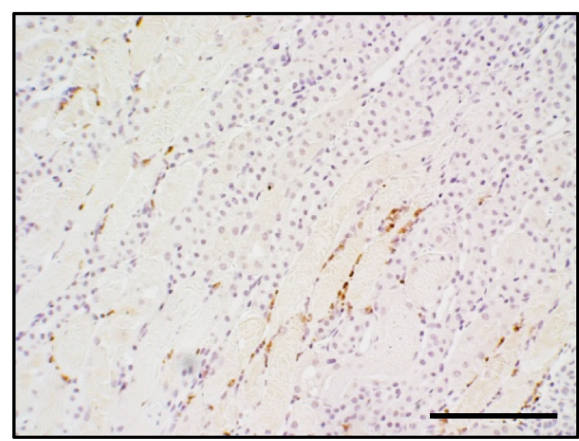

B

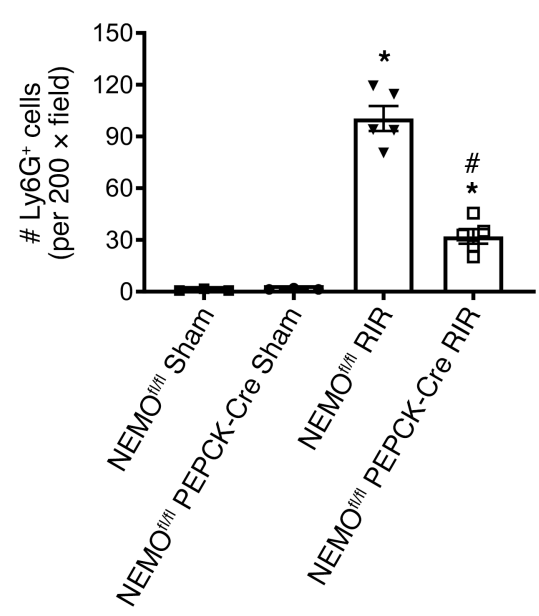

D

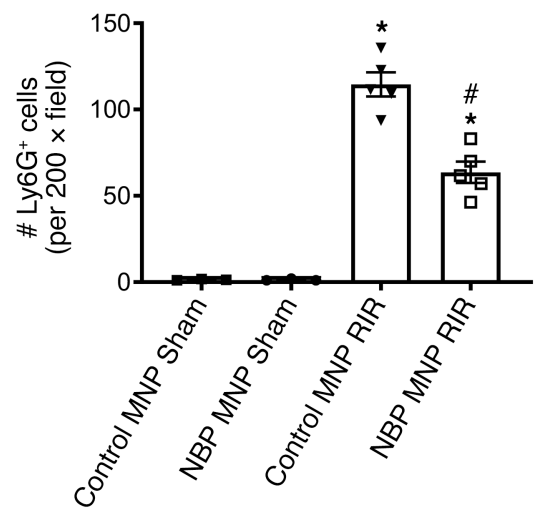

Figure 5. Kidney PT NEMO deletion or selective tubular delivery of NBP MNP decreases kidney neutrophil infiltration after ischemic AKI. (A) Representative images of IHC for neutrophils (dark brown, $\mathbf{A}$ and $\mathbf{C}$ ) and counts of infiltrating kidney neutrophils ( $\mathbf{B}$ and $\mathbf{D}$ ) in the kidneys of mice subjected to sham surgery $(N=3)$ or to 30 minutes of renal ischemia and 24 hours of reperfusion $(N=5, \times 200$ original magnification). (A and $\mathbf{B}) \mathrm{NEMO} \mathrm{O}^{\mathrm{fl} / \mathrm{fl}} \mathrm{WT}$ mice or renal PT NEMO-deficient mice subjected to sham surgery or renal IR. (C and D) C57BL/6 mice injected with control MNP or with $38 \mathrm{mg} /$ $\mathrm{kg}$ NBP MNP 6 hours before sham surgery ( $N$ $=3)$ or renal IR $(N=5)$. Scale bar: $200 \mu \mathrm{m}$. For statistical analysis, 1-way ANOVA plus Tukey's post hoc multiple-comparisons test was used to detect significant changes. ${ }^{*} P<0.05$ versus WT mice or control MNP-injected mice subjected to sham surgery. ${ }^{\sharp} P<0.05$ versus WT mice or control MNP-injected mice subjected to renal IR. Error bars represent 1 SEM. 
A
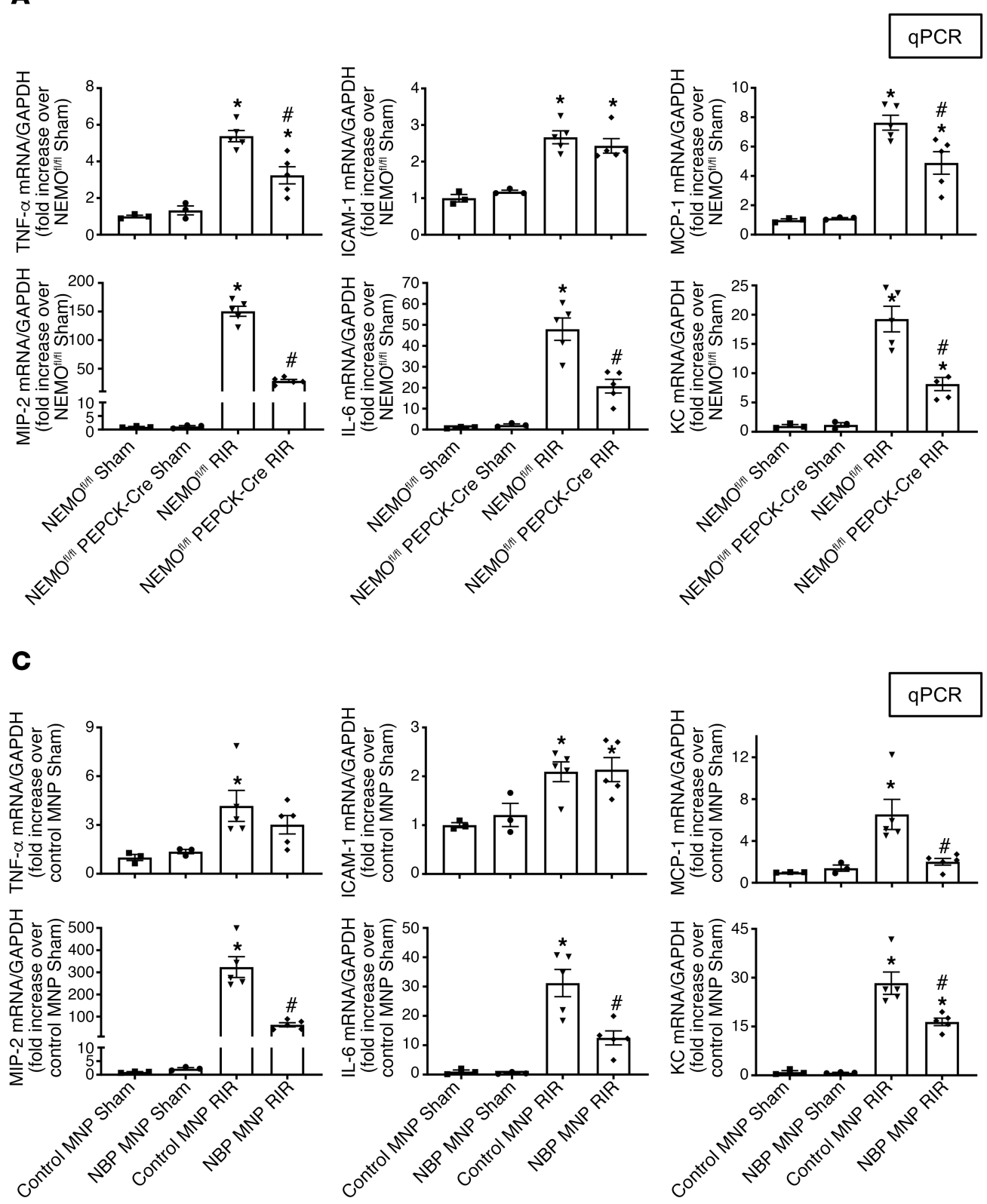
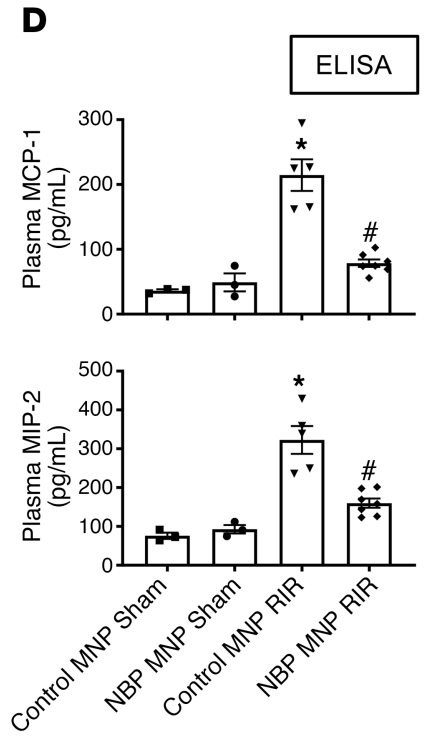

Figure 6. Kidney PT NEMO deletion or selective tubular delivery of NBP MNP attenuates kidney proinflammatory chemokine/cytokine induction after ischemic AKI. With quantitative RT-PCR (A and C), we measured the expression of proinflammatory cytokine and chemokine mRNAs in the kidney (KC, MCP-1, MIP-2, TNF- $\alpha$, IL-6, and ICAM-1), and with ELISA (B and D), we measured the plasma MCP-1 and MIP-2 levels 24 hours after sham surgery or 30 minutes after renal ischemia. (A and B) NEMO ${ }^{\mathrm{fl} / \mathrm{fl}}$ WT mice or renal PT NEMO-deficient mice subjected to sham surgery or renal IR. (C and $\left.\mathbf{D}\right)$ C57BL/6 mice injected with control MNP or with $38 \mathrm{mg} / \mathrm{kg}$ NBP MNP 6 hours before sham surgery $(N=3)$ or renal IR $(N=5)$. Fold increases in proinflammatory mRNAs normalized to GAPDH from quantitative RT-PCR reactions for each indicated mRNA are shown. For statistical analysis, 1-way ANOVA plus Tukey's post hoc multiple-comparisons test was used to detect significant changes. ${ }^{*} P<0.05$ versus WT mice or control MNP-injected mice subjected to sham surgery. ${ }^{\#} P<0.05$ versus WT mice or control MNP-injected mice subjected to renal IR. Error bars represent 1 SEM. KC, keratinocyte-derived cytokine; MCP-1, monocyte chemoattractive protein-1; MIP-2, macrophage inflammatory protein-2.

whole kidney and primary cultures of proximal tubules compared with vehicle-treated mouse kidney and proximal tubules (Figure 9A). Next, to determine whether rPAD4 targets renal PT NEMO to exacerbate ischemic AKI, we treated $\mathrm{NEMO}^{\mathrm{A} / \mathrm{fl}}$ control mice and renal PT NEMO-null mice with $10 \mu \mathrm{g}$ human $\mathrm{rPAD} 4$ 15 minutes before 20 minutes of renal IR injury. rPAD4 treatment exacerbated injury in NEMO ${ }^{\mathrm{A} / \mathrm{l}}$ mice subjected to 20 minutes renal IR ( $N=5-9$, Figure 9B). In contrast, rPAD4 failed to increase renal injury of mice deficient in renal PT NEMO subjected to 20 minutes of renal IR $(N=5-8)$. 
Sham surgery or 30 min renal ischemia and $24 \mathrm{~h}$ reperfusion
$\mathrm{NF}-\mathrm{kB} \mathrm{IHC}$

staining
A
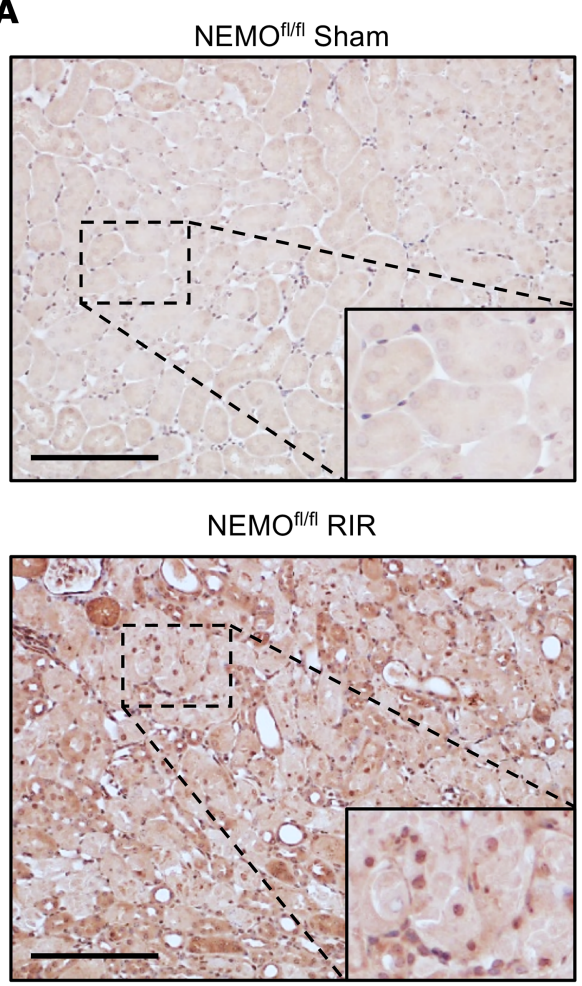

C

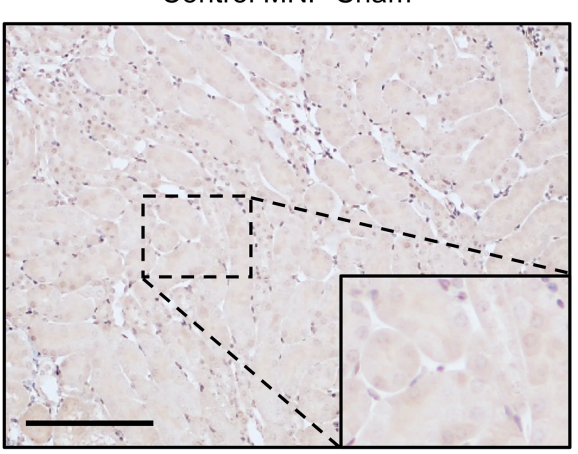

Control MNP RIR

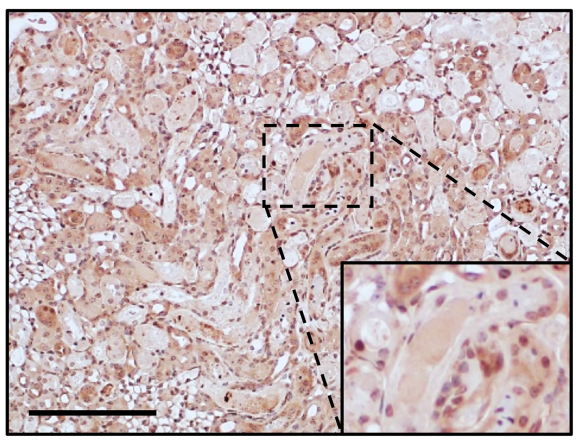

NEMO ${ }^{\text {fl/fl }}$ PEPCK-Cre Sham

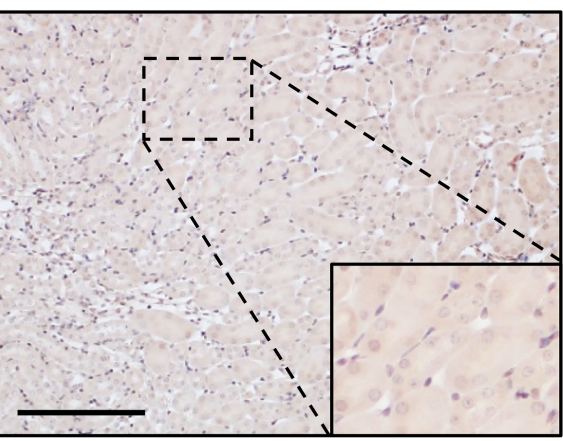

NEMO ${ }^{f / f l}$ PEPCK-Cre RIR

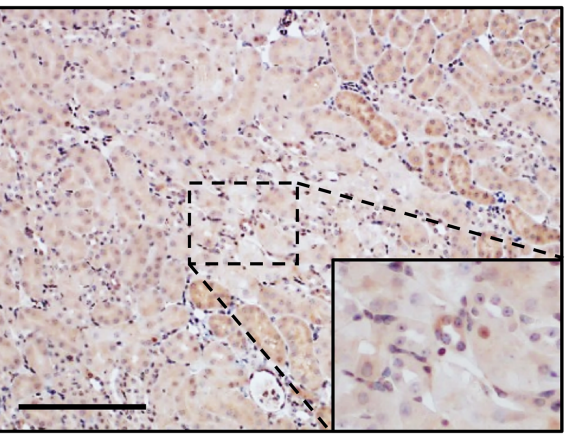

NBP MNP Sham

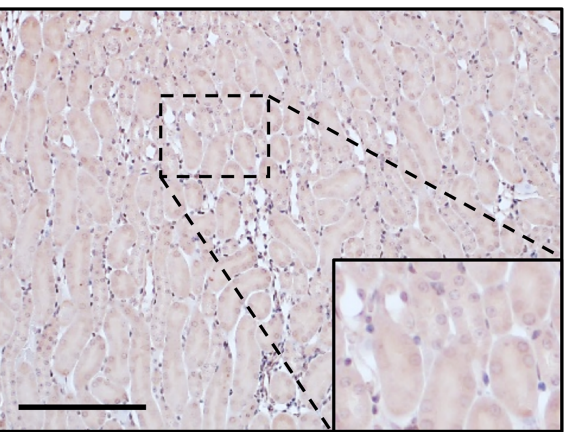

NBP MNP RIR

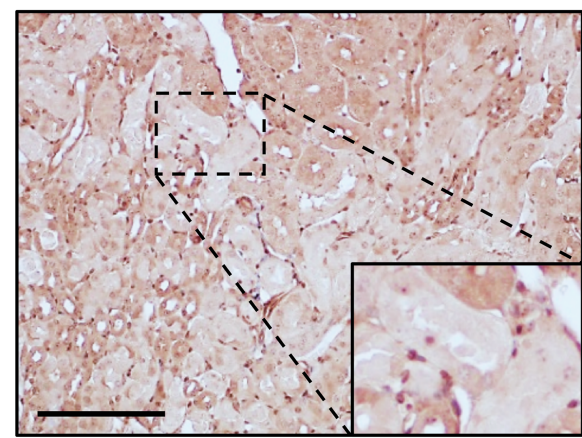

B

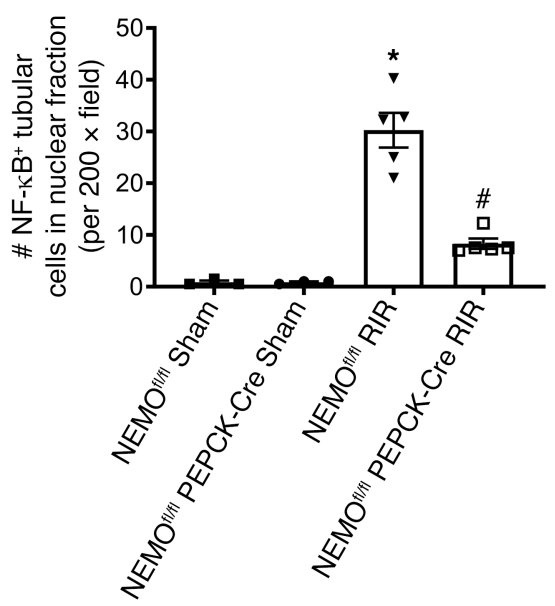

D

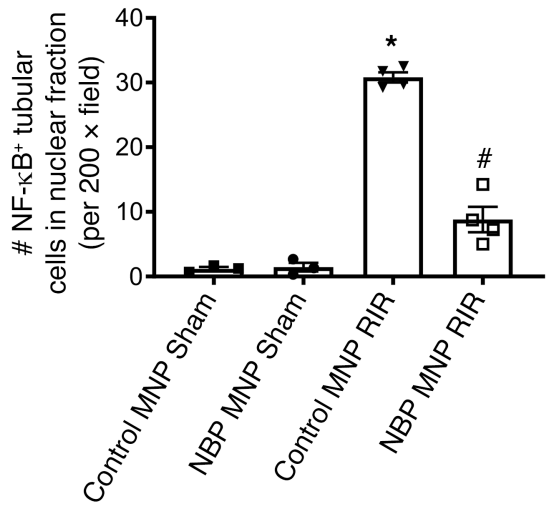

Figure 7. Kidney PT NEMO deletion or selective tubular delivery of NBP MNP attenuates renal tubular NF-KB activation after ischemic AKI. Representative images of IHC for NF-KB ( $A$ and $\mathbf{C}$ ) and counts of NF- $\kappa \mathrm{B}-$ positive tubular cells in nuclear fraction (B and $\mathbf{D}$ ) in the kidneys of mice subjected to sham surgery $(N=3)$ or to 30 minutes of renal ischemia and 24 hours of reperfusion ( $N=5, \times 200$ original magnification). Scale bar: $200 \mu \mathrm{m}$. For statistical analysis, 1-way ANOVA plus Tukey's post hoc multiple-comparisons test was used to detect significant changes. ${ }^{*} P<0.05$ versus WT mice or control MNP-injected mice subjected to sham surgery. ${ }^{\# P}<0.05$ versus WT mice or control MNP-injected mice subjected to renal IR. Error bars represent 1 SEM. 
Sham surgery or 30 min renal ischemia and $24 \mathrm{~h}$ reperfusion

\section{$\mathrm{p}-\mathrm{NF}-\mathrm{kB} \mathrm{IHC}$}

staining
A
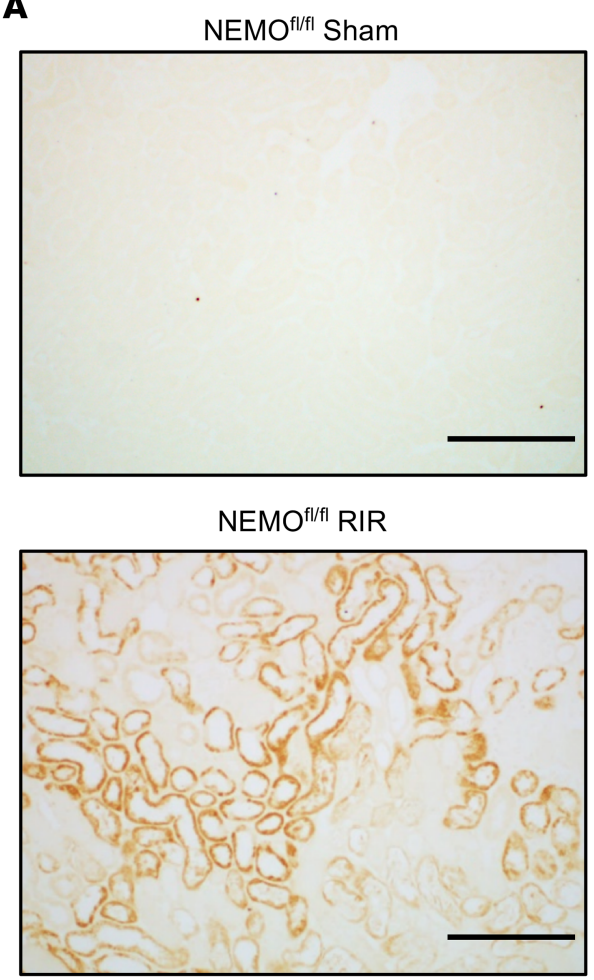

C

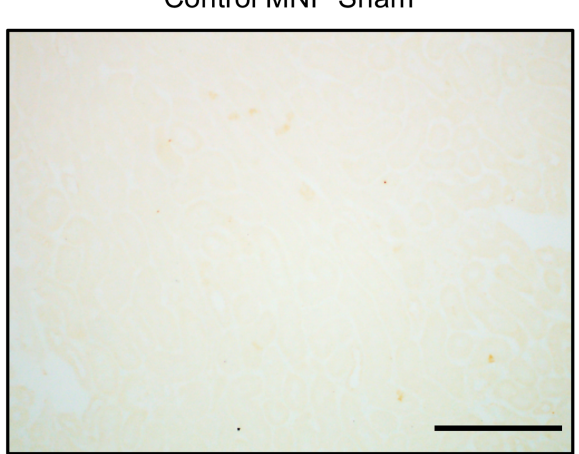

Control MNP RIR

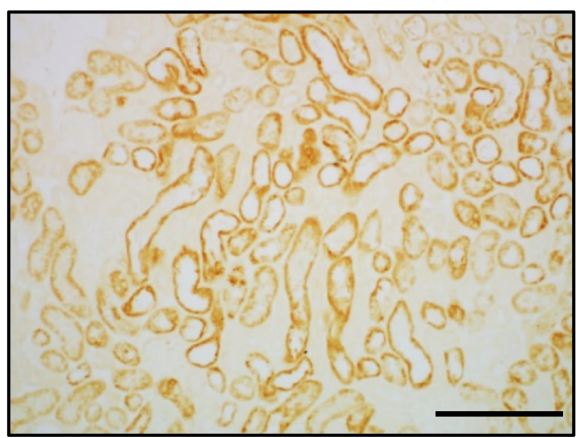

NEMO ${ }^{\text {fl/fl }}$ PEPCK-Cre Sham

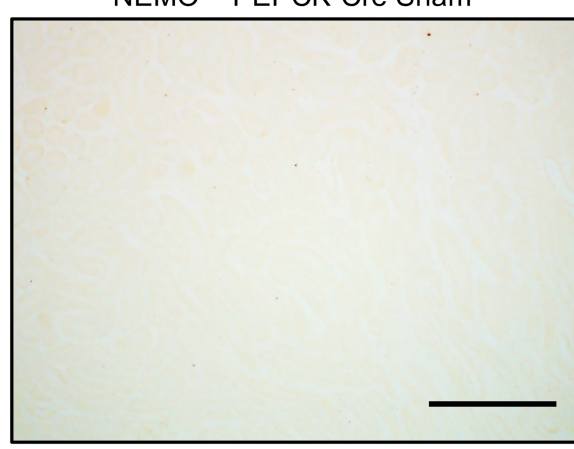

NEMO ${ }^{\text {fl/f }}$ PEPCK-Cre RIR

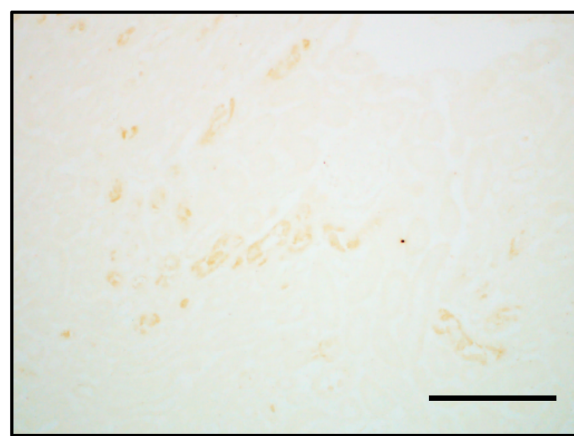

NBP MNP Sham

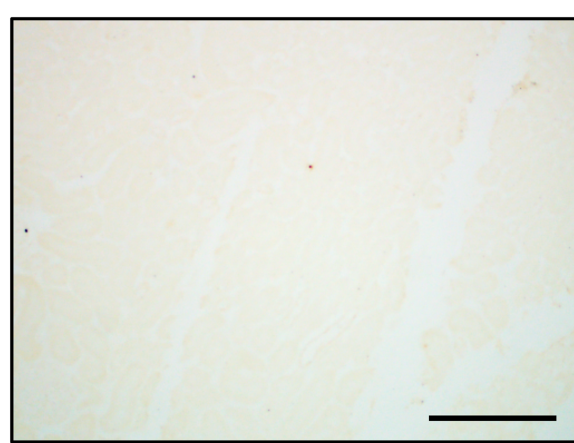

NBP MNP RIR

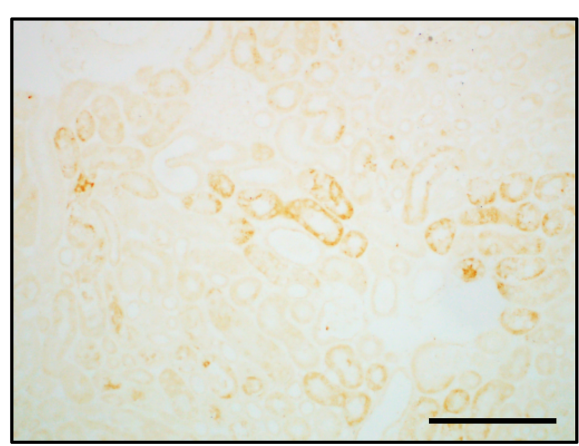

B

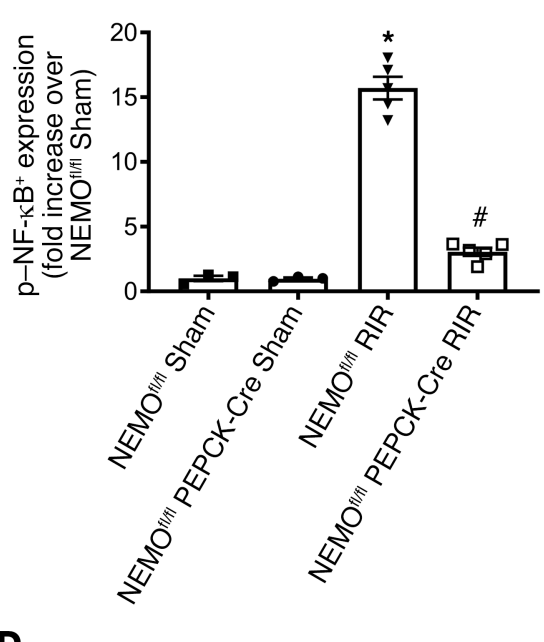

D

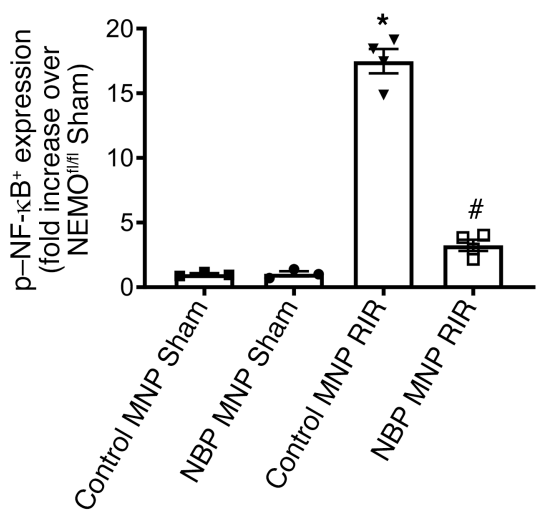

Figure 8. Kidney PT NEMO deletion or selective tubular delivery of NBP MNP attenuates renal tubular phospho-NF-кB activation after ischemic AKI. Representative images of IHC for phosphorylated NF- $\kappa B$ (p-NF- $\kappa B, A$ and $\mathbf{C}$ ) and counts of $\mathrm{p}-\mathrm{NF}-\mathrm{KB}(\mathbf{B}$ and $\mathbf{D})$ in the kidneys of mice subjected to sham surgery ( $N$ $=3$ ) or to 30 minutes of renal ischemia and 24 hours of reperfusion $(N=5, \times 200$ original magnification). Scale bar: $200 \mu \mathrm{m}$. For statistical analysis, 1-way ANOVA plus Tukey's post hoc multiple-comparisons test was used to detect significant changes. ${ }^{*} P<0.05$ versus WT mice or control MNP-injected mice subjected to sham surgery. ${ }^{\#} P<0.05$ versus WT mice or control MNP-injected mice subjected to renal IR. Error bars represent 1 SEM. 
A

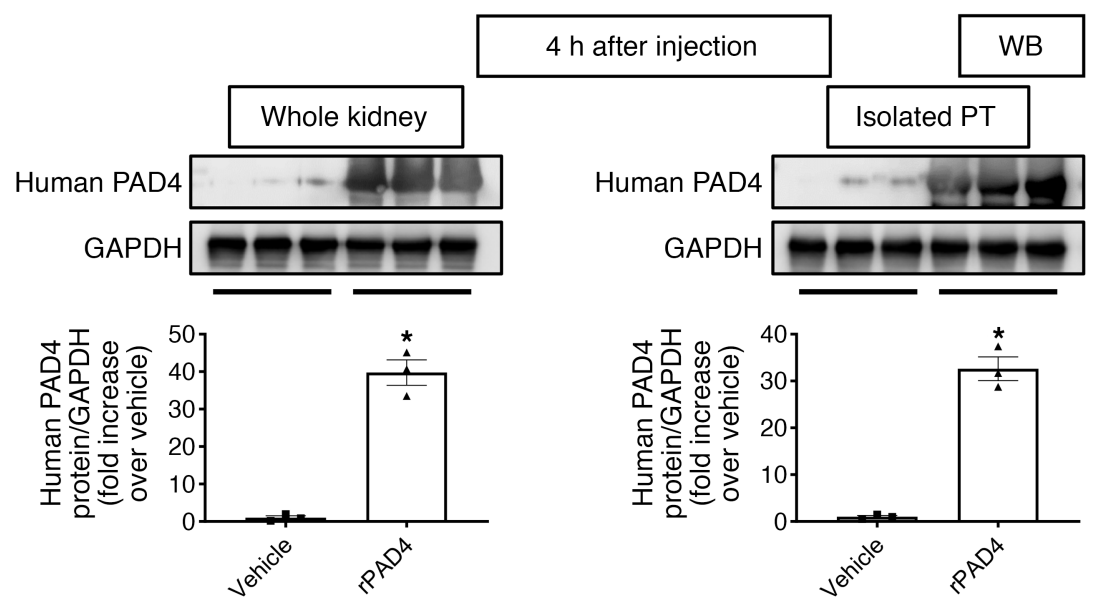

B
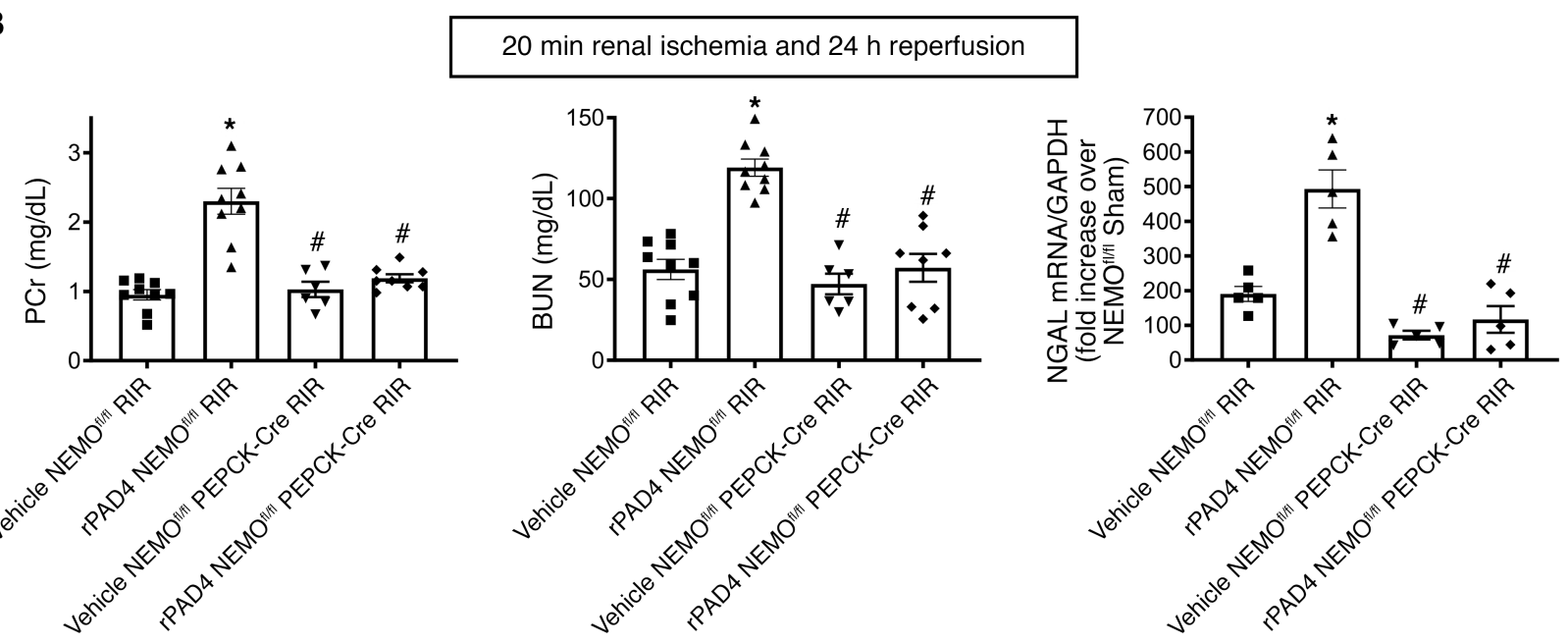

C
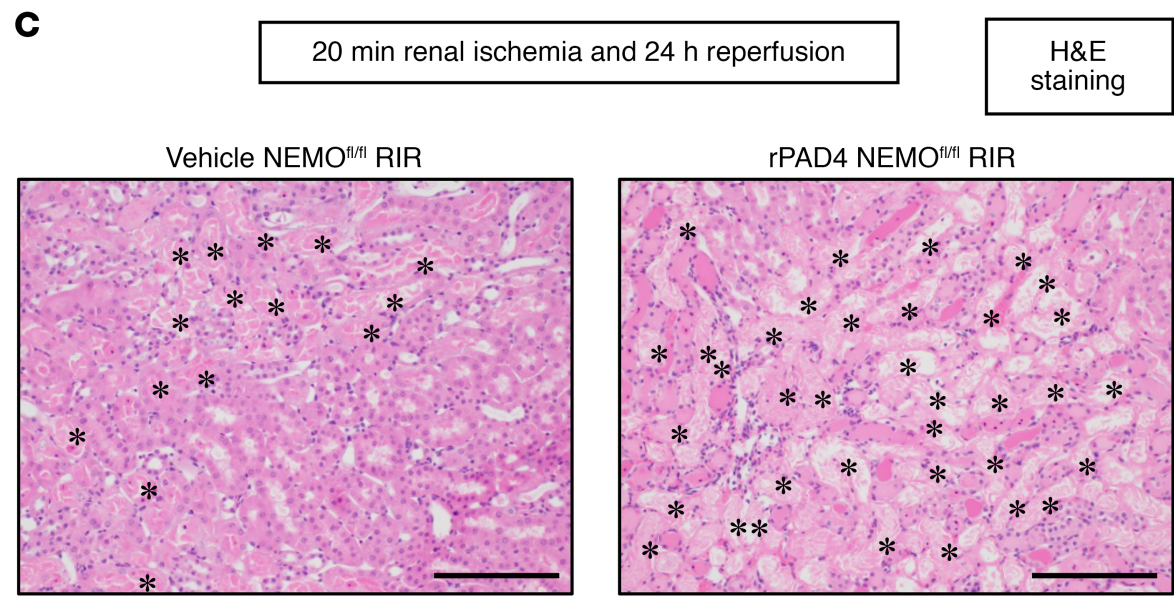

Vehicle NEMO ${ }^{\text {trft }}$ PEPCK-Cre RIR
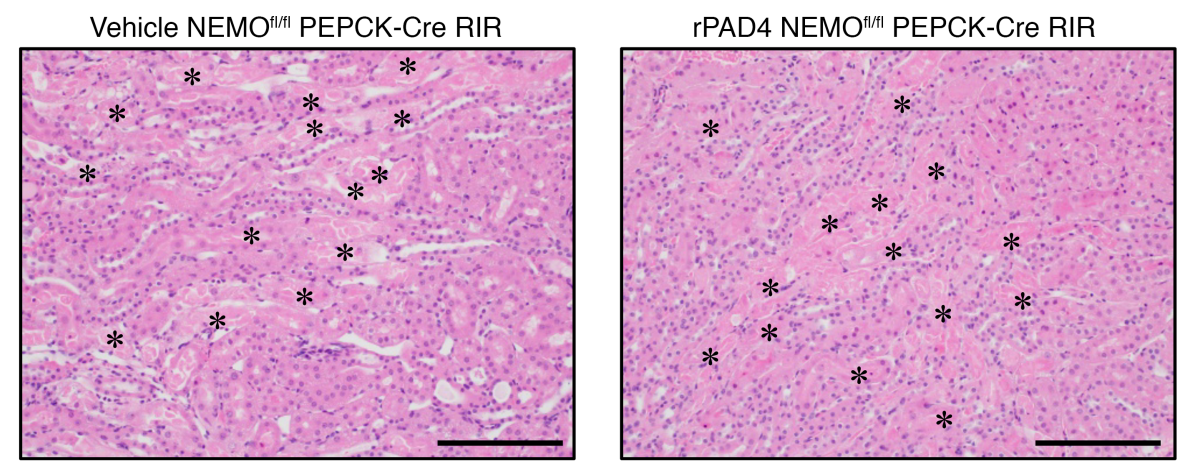

D

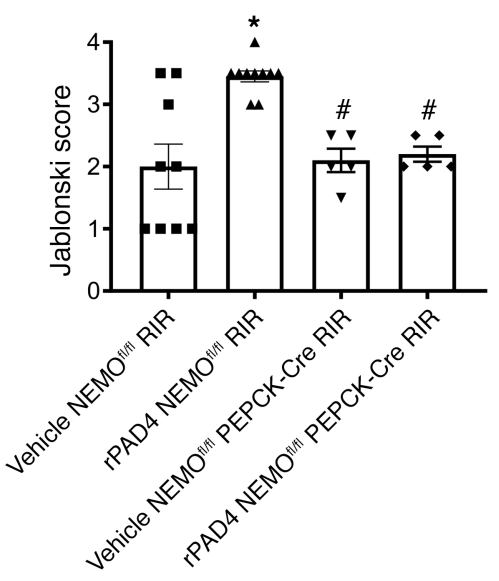


Figure 9. PAD4 exacerbates ischemic AKI in mice via PT NEMO activation. NEMO ${ }^{\mathrm{fl} / f \mid}$ WT or renal PT NEMO-deficient (NEMO ${ }^{\mathrm{fl} / \mathrm{fl}}$ PEPCK-Cre) mice were treated with vehicle (saline) or with recombinant PAD4 (rPAD4, $10 \mu \mathrm{g}$ i.v. 15 minutes before renal ischemia) and subjected to sham surgery or to 20 minutes of renal ischemia and 24 hours of reperfusion (RIR, $N=5-9$ ). rPAD4 treatment increased human PAD4 protein expressions (A) and renal injury measured by plasma creatinine, BUN, and kidney NGAL mRNA (B) and renal tubular necrosis (C and $\mathbf{D})$ in NEMO $\mathbf{O}^{\text {fl/fl }}$ mice. Severe tubular necrosis and proteinaceous casts $\left({ }^{*}\right)$ are indicated in $\mathrm{H} \& \mathrm{E}$ images ( $\times 200$ original magnification images). Scale bar: $200 \mu \mathrm{m}$. For statistical analysis of human PAD4 protein expressions (A), Student's $t$ test was used to detect significant changes. For other statistical analysis (B and D), 1-way ANOVA plus Tukey's post hoc multiple-comparisons test was used to detect significant changes. Scale bar: $200 \mu \mathrm{m}{ }^{*} P<0.05$ versus vehicle-treated NEMO ${ }^{\text {fl/fl }}$ mice subjected to renal IR injury. ${ }^{\#} P<0.05$ versus rPAD4-treated NEMO ${ }^{\mathrm{fl} / \mathrm{fl}}$ mice subjected to renal IR injury. Error bars represent $1 \mathrm{SEM}$.

As expected, the kidneys of $\mathrm{NEMO}^{\mathrm{f} / \mathrm{fl}}$ control mice treated with $10 \mu \mathrm{g}$ i.v. rPAD4 and subjected to renal IR showed increased tubular necrosis $(N=5-9$, Figure 9, C and D), renal tubular apoptosis (Figure 10, A and B), neutrophil infiltration (Figure 10, C and D), and kidney cytokine mRNA induction (Figure 11). In contrast, rPAD4 treatment did not increase tubular necrosis $(N=5$, Figure 9, $\mathrm{C}$ and $\mathrm{D})$, renal tubular apoptosis (Figure 10, A and B), neutrophil infiltration (Figure 10, C and D), or kidney cytokine mRNA induction (Figure 11) in renal PT NEMO-null mice.

Induction of canonical NF- $K B$-mediated proinflammatory signaling with NEMO activation. To determine whether PAD4 activates renal proximal tubular proinflammatory signaling via NEMO activation, we treated renal proximal tubule cells isolated from $\mathrm{NEMO}^{\mathrm{fl} / \mathrm{l}}$ mice or renal PT NEMO-null mice with $\mathrm{PPAD} 4(10 \mu \mathrm{g} / \mathrm{mL})$ for 6 hours. Figure 12A shows significant inductions of TNF- $\alpha$, ICAM-1, MCP-1, IL-6, KC, and MIP-2 mRNA in primary cultures of $\mathrm{NEMO}^{\mathrm{f} / \mathrm{fl}}$ renal proximal tubule cells treated with $\mathrm{rPAD}(N=3)$. In contrast, rPAD4 failed to induce these proinflammatory cytokine mRNAs in renal proximal tubules cells from renal PT NEMO-null mice. In addition, rPAD4 induced NF- $\mathrm{kB}$ p65 subunit nuclear translocation in renal proximal tubule cells from $\mathrm{NEMO}^{\mathrm{A} / \mathrm{fl}}$ mice but not from renal PT NEMO-null mice (Figure $12 \mathrm{~B}, N=3$ ).

We also treated primary cultures of renal proximal tubule cells with TNF- $\alpha$ or with LPS that can activate both canonical (classical) and noncanonical (transcription factor RelB or NEMO independent) NF- $\kappa \mathrm{B}$ pathways (18-20). Figure 12C shows that LPS induced TNF- $\alpha$, MCP-1, and MIP-2 mRNA expression in primary renal proximal cell cultures from $\mathrm{NEMO}^{\mathrm{f} / \mathrm{fl}}$ and renal PT NEMO-null mice. Similarly, NEMO deficiency did not attenuate TNF- $\alpha$-mediated proinflammatory cytokine induction in mouse renal tubule cells (data not shown).

To complement the gene deletion studies and show specific inhibition of the NEMO signaling pathway in renal tubular cells treated with NBP MNP, human proximal tubule $(\mathrm{HK}-2)$ cells were treated with rPAD4 for 6 hours with or without pretreatment of $10 \mu \mathrm{M} \operatorname{NBP} \operatorname{MNP}(N=3)$. We showed that $\mathrm{NBP}$ MNP completely prevented rPAD4-mediated induction of TNF- $\alpha$, ICAM-1, MCP-1, IL-6, IL-8, and MIP2 mRNA (Figure 13).

Finally, we treated primary cultures of bone marrow-derived macrophages isolated from $\mathrm{NEMO}^{\mathrm{f} / \mathrm{fl}}$ and renal PT NEMO-null mice with $10 \mu \mathrm{g} / \mathrm{mL}$ rPAD4. Demonstrating renal proximal tubule-specific NEMO deletion further, rPAD4 induced proinflammatory cytokine mRNAs in $\mathrm{NEMO}^{\mathrm{f} / \mathrm{fl}}$ and renal PT NEMO-null mouse bone marrow-derived macrophages (Figure 14).

\section{Discussion}

We previously demonstrated that renal proximal tubule cells not only express nuclear PAD4, but its expression is upregulated after renal IR via ATP-mediated activation of P2X7 receptors $(12,14)$. Inhibition of genetic deletion of PAD4 attenuated renal IR injury in mice, significantly reducing renal tubular inflammation, necrosis, and apoptosis (12-14). Activated renal tubular PAD4 gets translocated to the cytosol after IR and in the cytosol, PAD4 selectively promotes the activity of one of the key regulators of $\mathrm{NF}-\mathrm{\kappa B}$ activation IKK $\gamma$ (also called NEMO) via citrullination, resulting in nuclear translocation of NF- $\mathrm{BB}(15)$. NEMO neutralization with a specific binding peptide attenuated PAD4-mediated NF- $\kappa B$ nuclear translocation and inflammatory cytokine generation.

Our previous findings suggest a potential therapeutic role for NBP therapy to protect against ischemic AKI. However, systemic administration of NBP will inhibit NEMO in every cell type in the body and may not be a viable option as a treatment for ischemic AKI. Although kidney NEMO may exacerbate renal IR injury by inducing apoptosis and inflammation, other cell types in the kidney may benefit from NEMO signaling. Indeed, long-term systemic NEMO inhibition or deletion may not produce antiinflammatory effects in all cell types and may produce detrimental effects in extrarenal cell types and organs. For example, lymphocyte NEMO deletion increases intrarenal Th17 cells and exacerbates ischemic AKI in 
A

20 min renal ischemia and $24 \mathrm{~h}$ reperfusion

TUNEL staining

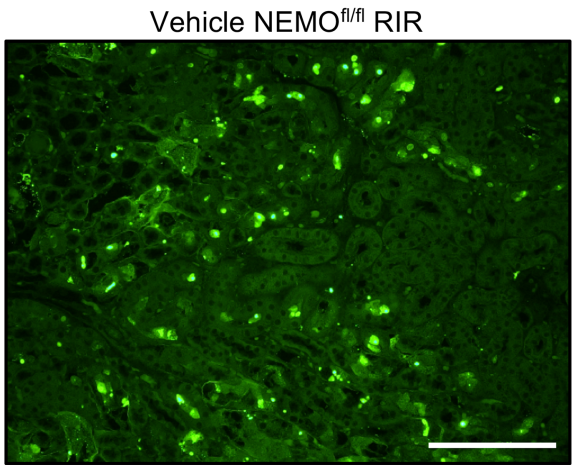

Vehicle NEMO fl/fl PEPCK-Cre RIR
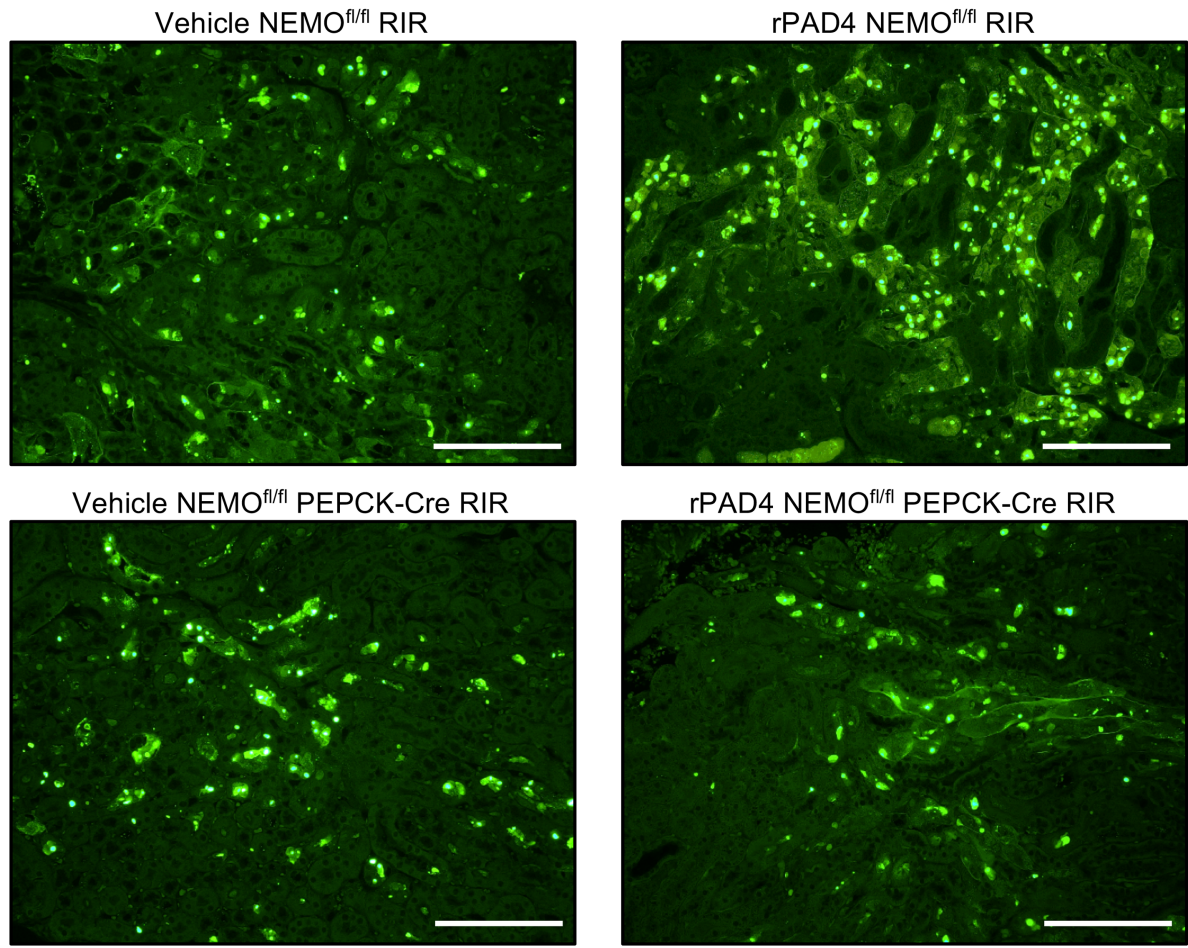

rPAD4 NEMO ${ }^{\text {fl/fl }}$ PEPCK-Cre RIR

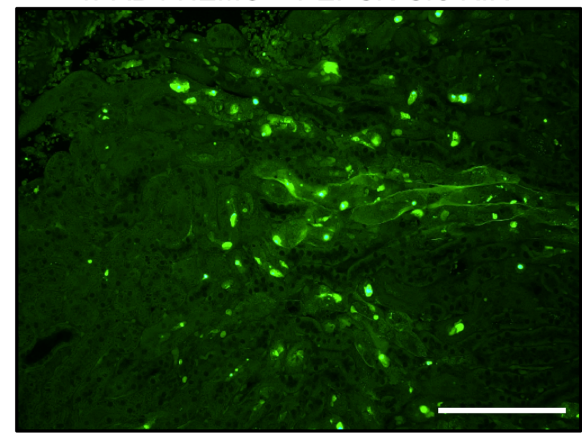

C

20 min renal ischemia and $24 \mathrm{~h}$ reperfusion

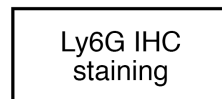

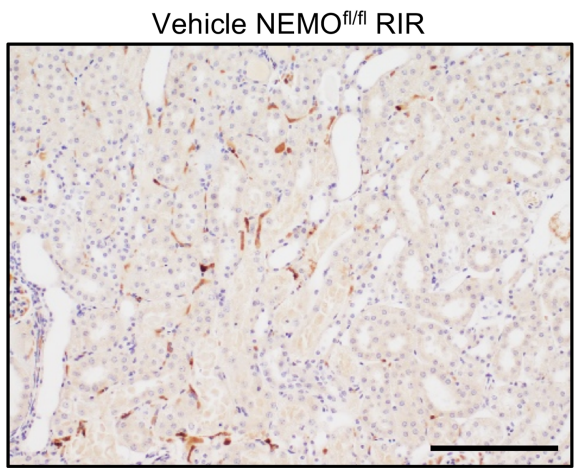

Vehicle NEMO ${ }^{\text {fl/fl }}$ PEPCK-Cre RIR

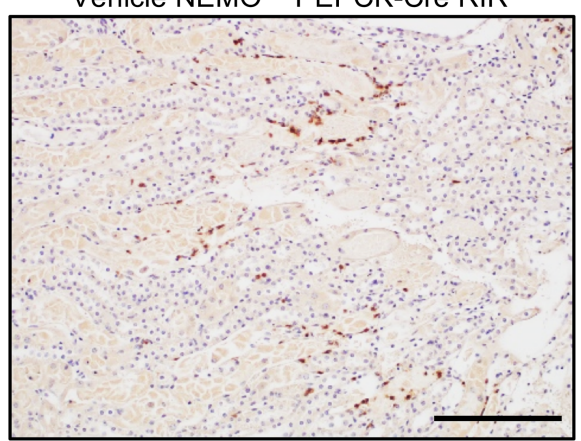

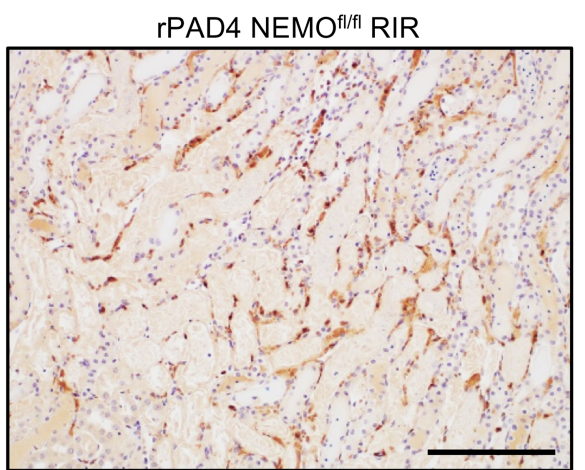

rPAD4 NEMO ${ }^{\text {fl/fl }}$ PEPCK-Cre RIR

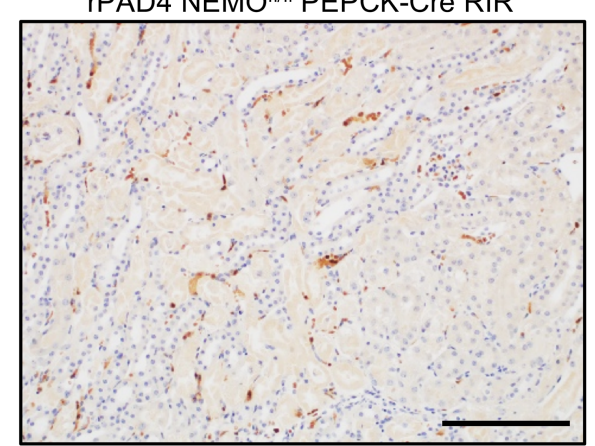

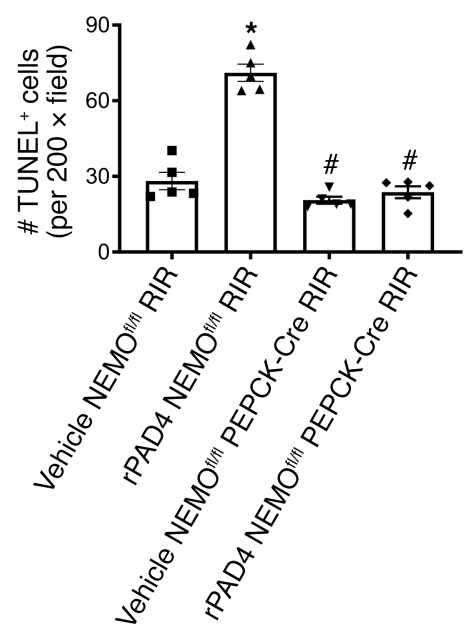

D

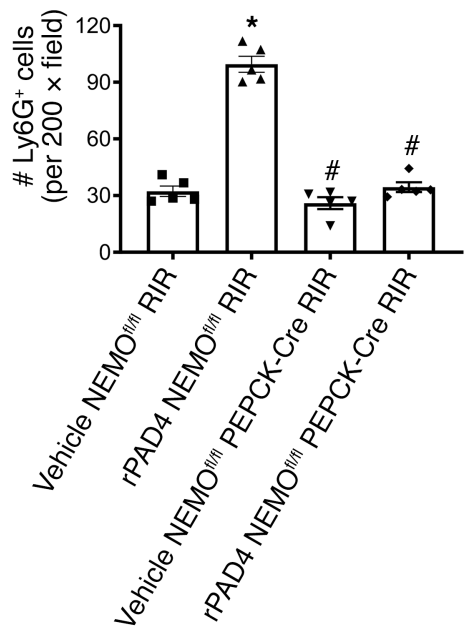

Figure 10. PAD4 exacerbates ischemic AKI-induced renal tubular apoptosis and neutrophil infiltration in mice via PT NEMO activation. NEMO ${ }^{f / / f l}$ WT or renal PT NEMO-deficient (NEMO ${ }^{\mathrm{fl} / \mathrm{fl}}$ PEPCK-Cre) mice were treated with vehicle (saline) or with recombinant PAD4 (rPAD4, $10 \mu$ g i.v. 15 minutes before renal ischemia) and subjected to sham surgery or to 20 minutes of renal ischemia and 24 hours of reperfusion (RIR, $N=5-9$ ). rPAD4 treatment exacerbated renal tubular apoptosis (A and $\mathbf{B}$ ) and neutrophil infiltration ( $\mathbf{C}$ and $\mathbf{D}$ ) in NEMO ${ }^{f / / f l}$ mice. TUNEL and neutrophil IHC show $\times 200$ original magnification images. Scale bar: $200 \mu \mathrm{m}$. For statistical analysis, 1-way ANOVA plus Tukey's post hoc multiple-comparisons test was used to detect significant changes. Scale bar: $200 \mu \mathrm{m}^{*} P<$ 0.05 versus vehicle-treated $\mathrm{NEMO} \mathrm{fl}^{\mathrm{fl} / \mathrm{m}}$ mice subjected to renal IR injury. ${ }^{\#} P<0.05$ versus rPAD4-treated NEMO ${ }^{\mathrm{fl} / \mathrm{fl}}$ mice subjected to renal IR injury. Error bars represent 1 SEM. 


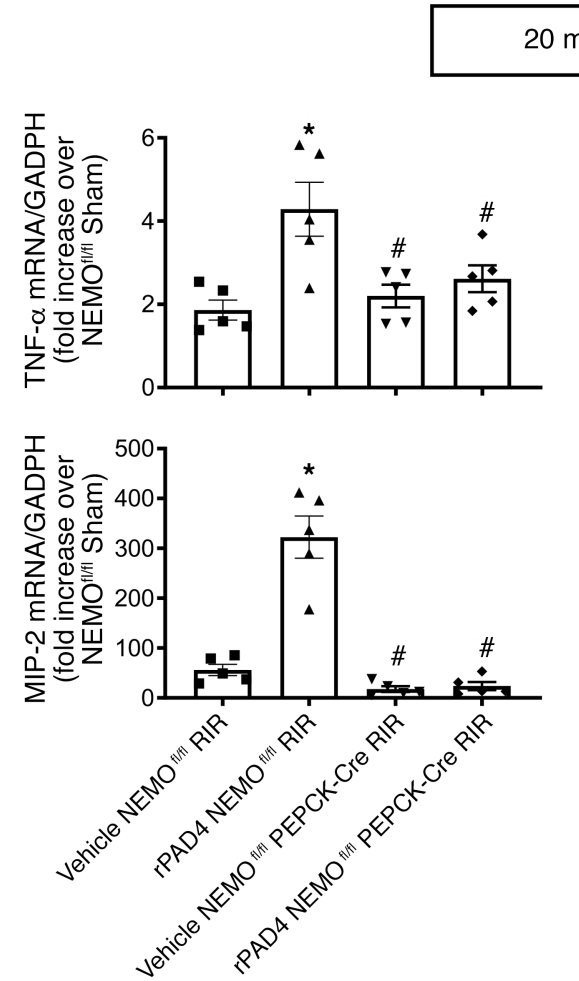

20 min renal ischemia and $24 \mathrm{~h}$ reperfusion
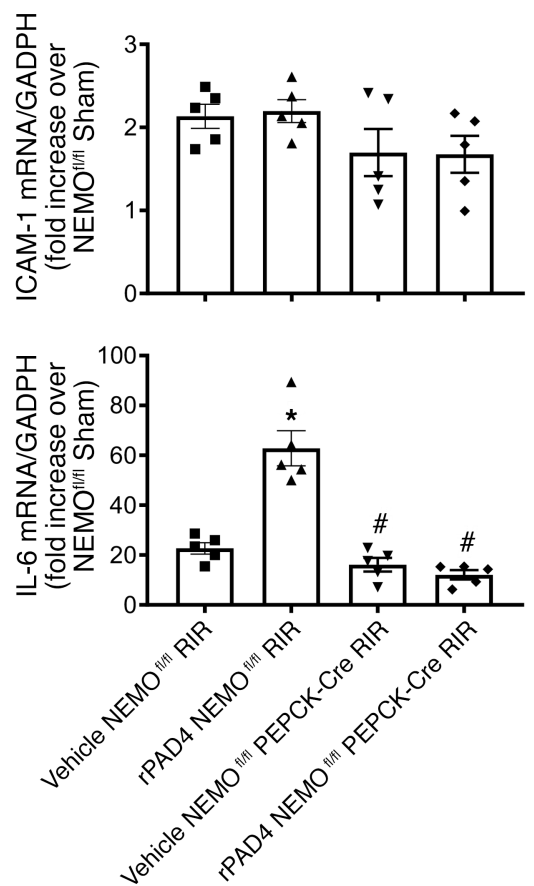

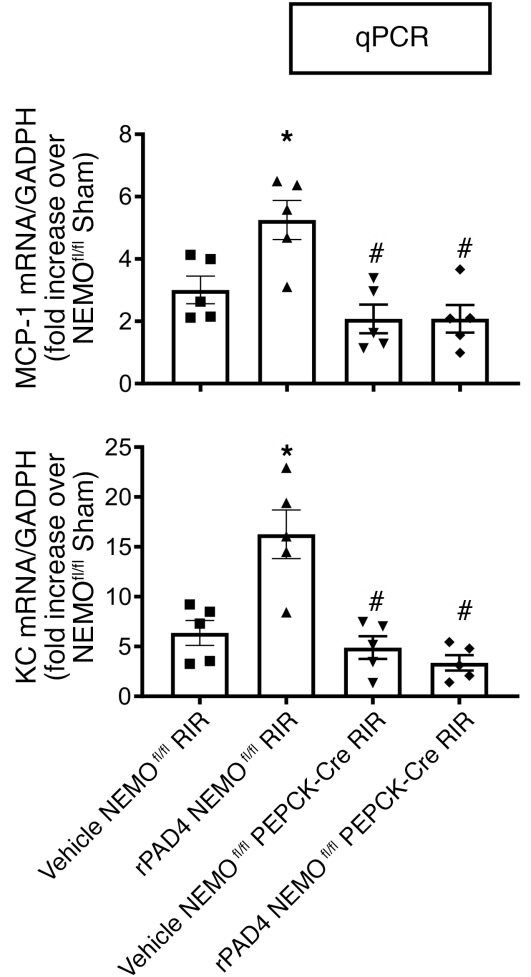

Figure 11. PAD4 exacerbates ischemic AKI-induced renal tubular inflammatory cytokine generation in mice via PT NEMO activation. NEMO ${ }^{f / / f l}$ WT or renal PT NEMO-deficient (NEMO ${ }^{\mathrm{fl} / \mathrm{fl}}$ PEPCK-Cre) mice were treated with vehicle (saline) or with recombinant PAD4 (rPAD4, $10 \mu \mathrm{g}$ i.v. 15 minutes before renal ischemia) and subjected to sham surgery or to 20 minutes of renal ischemia and 24 hours of reperfusion (RIR, $N=5-9$ ). rPAD4 treatment exacerbated kidney proinflammatory cytokines and chemokines except ICAM-1 mRNA induction in NEMO ${ }^{\mathrm{fl} / \mathrm{fl}}$ mice. For RT-PCR, fold increases in proinflammatory mRNAs normalized to GAPDH from quantitative RT-PCR reactions for each indicated mRNA are shown. For statistical analysis, 1-way ANOVA plus Tukey's post hoc multiple-comparisons test was used to detect significant changes. Scale bar: $200 \mu \mathrm{m}{ }^{*} P<0.05$ versus vehicle-treated NEMO ${ }^{\mathrm{fl} / \mathrm{fl}}$ mice subjected to renal IR injury. ${ }^{\#} P<0.05$ versus rPAD4-treated NEMO ${ }^{\text {fl/fl }}$ mice subjected to renal IR injury. Error bars represent 1 SEM.

mice (21). In addition, myeloid NEMO deletion results in osteoporosis via upregulation of transcriptional repressors (22). Moreover, NEMO activity is critical for thyroid function, and thyroid-specific NEMO deletion causes hypothyroidism in mice (23). Finally, hepatocyte NEMO deletion causes steatohepatitis and liver cancer in mice (24). These studies show that systemic administration of a NEMO antagonist may have limited therapeutic potential for ischemic AKI.

Since NEMO expression is ubiquitous among many organs and cell types even in the kidney, it remains unclear whether renal PT NEMO plays a critical role in ischemic AKI and subsequent renal tubular inflammation. Our current study showed that renal PT NEMO (IKK $\gamma$ ) plays a critical role in ischemic AKI by promoting renal tubular inflammation, resulting in increased renal tubular cell death, apoptosis, and neutrophil infiltration. Our findings are based on 2 distinct approaches: 1) we created mice with renal tubular-specific deletion of NEMO and 2) we selectively delivered NBP to renal proximal tubule cells using NBP encapsulated in MNPs. Mice deficient in renal PT NEMO and mice treated with NBP MNP were significantly protected against ischemic AKI, having reduced renal tubular inflammation, necrosis, and apoptosis.

Renal tubular NF- $\mathrm{kB}$ activation leads to transcription of several proinflammatory cytokines, including neutrophil-attracting IL-8/KC and MIP-2 (also called CXCL8 and CXCL2, respectively) (25, 26). IKK $\gamma$,

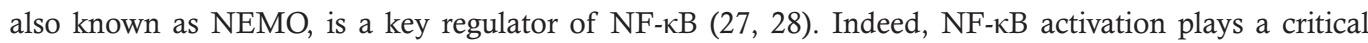
role in generating the inflammatory response as a key transcription factor for several proinflammatory chemokines. However, NF- $\mathrm{BB}$ is also a critical transcription factor for cell survival, proliferation, and differentiation $(29,30)$. Therefore, global NF- $\mathrm{KB}$ inhibition may decrease the renal inflammatory response after IR, but also may reduce renal cell proliferation and survival (31). Therefore, selective inhibition of the proinflammatory $\mathrm{NF}-\kappa \mathrm{B}$ signaling pathway would be required to protect against the inflammatory response 
A
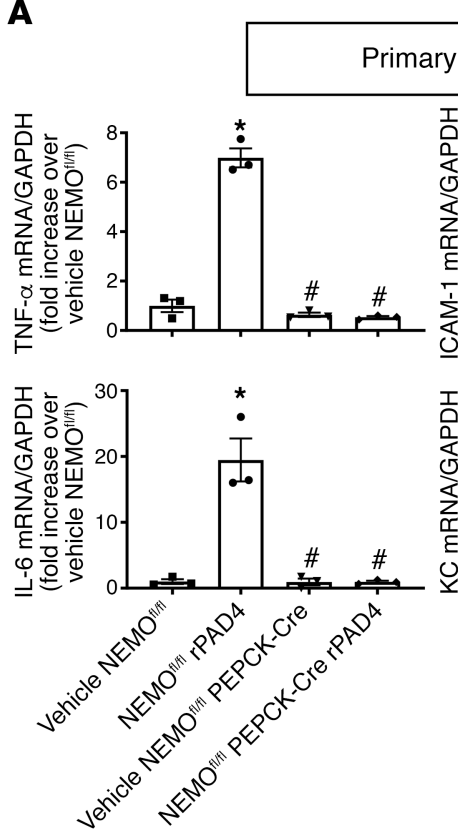
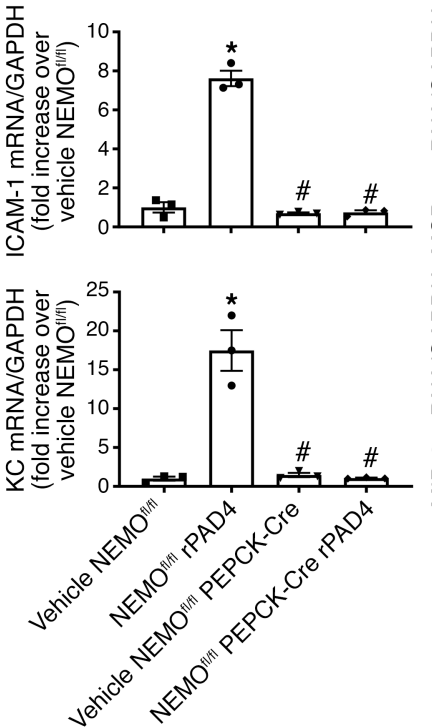

B

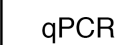

WB

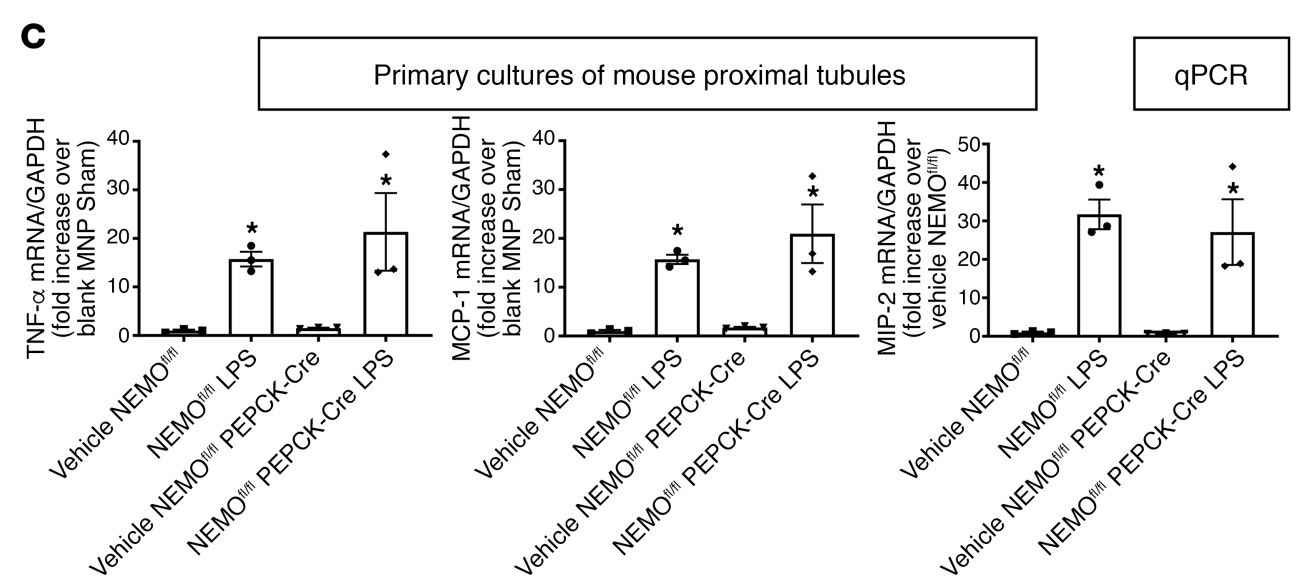

Figure 12. NEMO-mediated induction of renal proximal tubular NF-кB proinflammatory signaling in mouse renal proximal tubule cells. Primary cultures of renal proximal tubule cells from NEMO ${ }^{\text {fl/fl }}$ WT or renal PT NEMO-deficient (NEMO ${ }^{\mathrm{fl} / \mathrm{fl}}$ PEPCK-Cre) mice were treated with recombinant PAD4 (rPAD4, $10 \mu \mathrm{g} / \mathrm{mL}$ ) for 6 hours (A) or 4 hours (B) or with lipopolysaccharides (LPS, $10 \mu \mathrm{g} / \mathrm{mL}$ ) for 6 hours (C). (A) With RT-PCR, we measured the expressions of TNF- $\alpha$, ICAM-1, MCP-1, IL-6, KC, and MIP-2 mRNAs. Fold increases in mRNAs normalized to GAPDH from quantitative RT-PCR reactions for each indicated mRNA $(N=3)$ are shown. (B) A representative immunoblotting experiment for nuclear p65 NF- $K B$ subunit (top) and band intensity quantifications normalized to histone $\mathrm{H3}(N=3$, bottom). (C) With RT-PCR, we measured the expression of TNF- $\alpha$, MCP-1, and MIP-2 mRNAs. Fold increases in mRNAs normalized to GAPDH from quantitative RT-PCR reactions for each indicated mRNA $(N=3)$ are shown. For statistical analysis, 1-way ANOVA plus Tukey's post hoc multiple-comparisons test was used to detect significant changes. ${ }^{*} P<0.05$ versus vehicle-treated NEMO ${ }^{f / / f l}$ mice. ${ }^{\#} P<0.05$ versus rPAD4-treated NEMO ${ }^{\text {fl/fl }}$ mice. Error bars represent $1 \mathrm{SEM}$.

after renal IR. Relevant to potential therapy, selective NEMO inhibition with NBP selectively attenuates proinflammatory gene expression and improves kidney injury without negative effects on renal tubular cell proliferation and survival (15). Interestingly, Markó et al. demonstrated that selective IкB $\alpha$ suppression leading to NF-kB inhibition in tubular epithelial cells protected against ischemic kidney injury with reduced apoptotic/necrotic tubular cell death and inflammation (32). Their study agrees with the renal protective effects of IKK $\gamma$ deletion or inhibition in mice subjected to ischemic AKI in our study. We showed here that renal PT NEMO deletion resulted in total loss of rPAD4-mediated proinflammatory cytokine mRNA induction in renal proximal tubule cells. In contrast, renal PT NEMO deletion failed to attenuate proinflammatory cytokine mRNA induction in response to TNF- $\alpha$ or to LPS, further demonstrating that PAD4 selectively activated the canonical NF-kB pathway via NEMO citrullination. Furthermore, NBP 


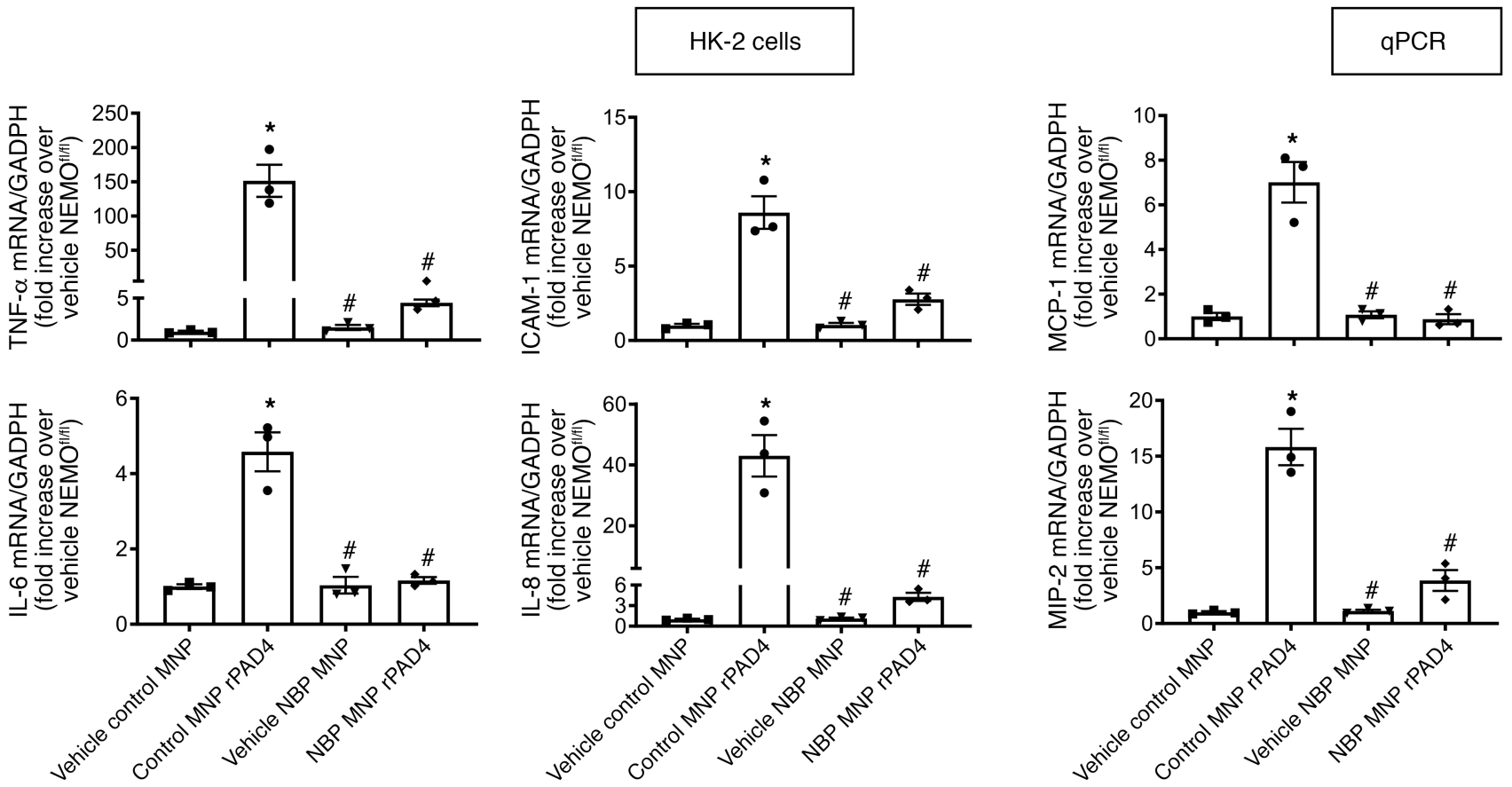

Figure 13. NEMO-mediated induction of renal proximal tubular NF-KB proinflammatory signaling in human renal proximal tubule cells. Human proximal tubule (HK-2) cells were treated with $10 \mu \mathrm{g} / \mathrm{mL}$ rPAD4 for 6 hours with or without pretreatment of $10 \mu \mathrm{M}$ NBP MNPs $(N=3)$. The expressions of TNF- $\alpha$, ICAM-1, MCP-1, IL-6, IL-8, and MIP-2 mRNAs were measured with RT-PCR. Fold increases in mRNAs normalized to GAPDH from quantitative RT-PCR reactions for each indicated mRNA $(N=3)$ are shown. For statistical analysis, 1-way ANOVA plus Tukey's post hoc multiple-comparisons test was used to detect significant changes. ${ }^{*} P<0.05$ versus control MNP-treated cells. ${ }^{\#} P<0.05$ versus control MNP-treated cells. Error bars represent 1 SEM.

MNP blocked rPAD4-mediated proinflammatory cytokine induction in human renal proximal tubule cells. Taken together, our findings further support that PAD4 induces inflammatory cytokine signaling in renal proximal tubular cells via NEMO-dependent mechanisms and that renal PT NEMO plays a critical role in proinflammatory cytokine regulation via the canonical $\mathrm{NF}-\kappa \mathrm{B}$ pathway.

Many promising preclinical studies failed to show efficacy in the clinical setting $(33,34)$. A major factor in the lack of successful translation from bench research to clinical therapy is clearly the complex nature of clinical AKI in patients with multiple comorbidities in comparison with simplified laboratory models of AKI in healthy animals $(35,36)$. Another reason for lack of success may be that systemic administration of drugs to treat clinical AKI will target every organ system and multiple cell types. Drugs that protect renal epithelial cells may produce unwanted detrimental effects in other cell types (e.g., myeloid cells, hepatocytes) as discussed above. Finally, drugs given at nontoxic doses may not achieve therapeutically adequate levels to treat or prevent ischemic AKI. Here, we used a strategy to selectively deliver NBP in adequate therapeutic levels in renal proximal tubular cells with NBP MNP. We previously showed that systemic injection of $5 \mathrm{mg} / \mathrm{kg} \mathrm{NBP}$ in mice subjected to renal IR protected against ischemic AKI (15). It is exciting and clinically relevant that MNP encapsulating a significantly lower dose of NBP (8 or $16 \mu \mathrm{g} / \mathrm{kg}$ NBP) compared with doses used for systemic injection provided powerful protection against ischemic AKI in mice by attenuating renal tubular necrosis, inflammation, and apoptosis. Furthermore, we determined that NBP MNP delivered 15 minutes after reperfusion was almost as protective as NBP MNP given 6 hours before renal ischemia, providing a basis for even greater clinical significance.

MNPs are PEG-coated poly(lactic-co-glycolic acid) (PLGA) polymer particles with diameters of approximately 300-400 $\mathrm{nm}(37,38)$. We showed previously that MNPs localize to the basolateral region of proximal tubule epithelial cells preferentially over other organs ( $>30$-fold selectivity) and remain in the kidney for approximately 7 days after injection $(37,39)$. These findings have significant clinical potential in that renal proximal tubular cells are the major site of injury in ischemic AKI (40, 41). Also clinically relevant, MNP treatment did not have a detrimental effect on renal or hepatic function, inflammation, or hematological problems $(37,38,42)$. Moreover, we recently showed with intravital imaging studies that 


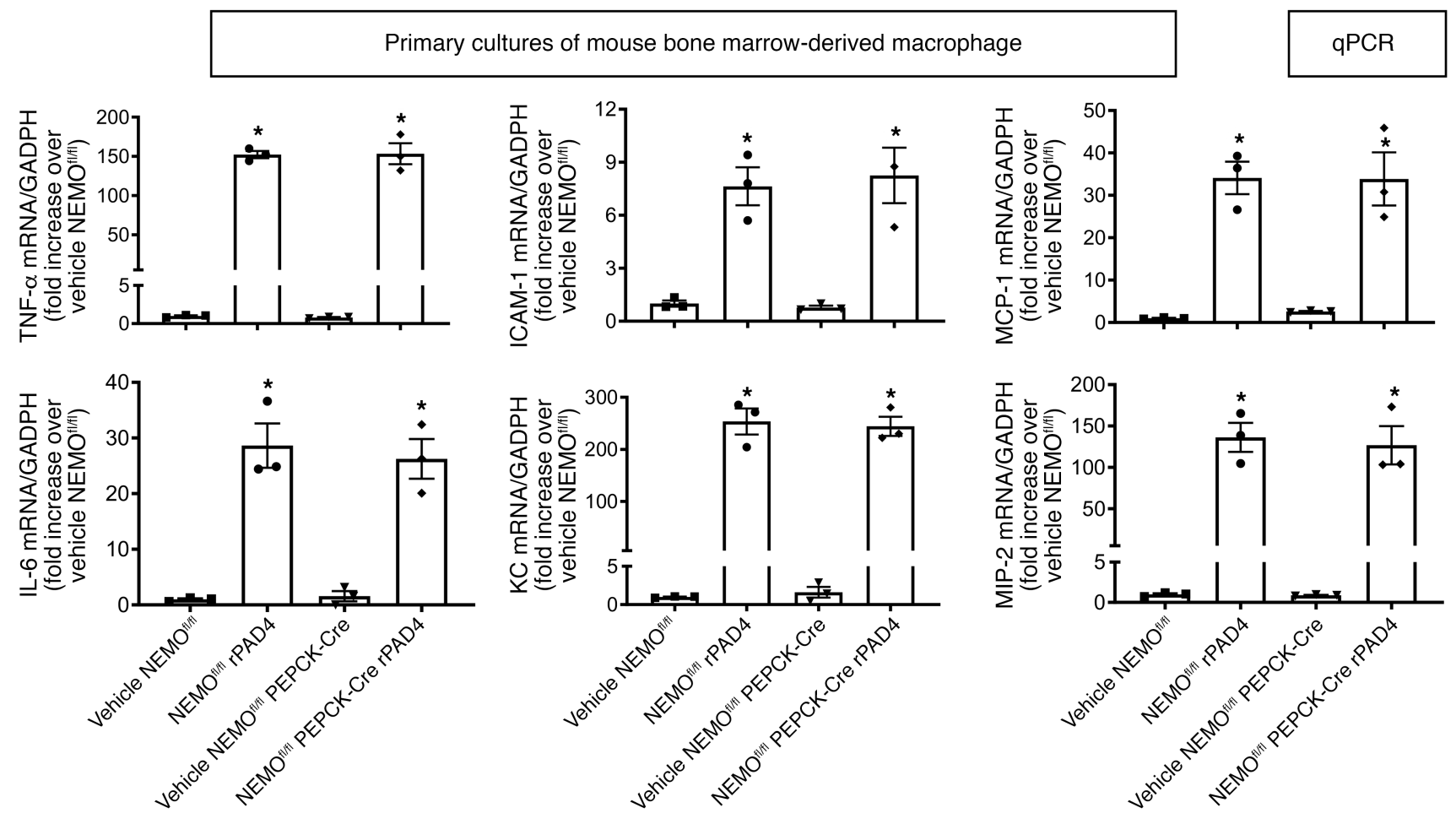

Figure 14. Renal PT NEMO does not mediate bone marrow-derived macrophage proinflammatory signaling. Freshly isolated bone marrow-derived macrophages from NEMO ${ }^{f / f l}$ WT or renal PT NEMO-deficient (NEMO ${ }^{\text {fl/fl }}$ PEPCK-Cre) mice were treated with recombinant PAD4 (rPAD4, $10 \mu \mathrm{g} / \mathrm{mL}$ ) for 6 hours and we measured the expression of TNF- $\alpha$, ICAM-1, MCP-1, IL-6, KC, and MIP-2 mRNAs with RT-PCR. Fold increases in mRNAs normalized to GAPDH from quantitative RT-PCR reactions for each indicated mRNA $(N=3)$ are shown. For statistical analysis, 1-way ANOVA plus Tukey's post hoc multiple-comparisons test was used to detect significant changes. ${ }^{*} P<0.05$ versus vehicle-treated NEMO ${ }^{f / f f}$ or control MNP-treated cells. Error bars represent $1 \mathrm{SEM}$.

kidneys subjected to renal IR maintained approximately 30-fold kidney-specific delivery of MNPs compared with other organ studies (39). Therefore, it appears that renal tubular necrosis and inflammation have no impact on kidney-selective delivery of MNPs.

One potential concern may be that PEPCK-Cre recombinase is expressed in renal proximal cells and in a subset of periportal hepatocytes (16). Indeed, we showed in this study that hepatic NEMO mRNA expression was approximately 32\% less in $\mathrm{NEMO}^{\mathrm{f} / \mathrm{fl}}$ PEPCK-Cre mice compared with $\mathrm{NEMO}^{\mathrm{fl} / \mathrm{fl}}$ mice. In contrast, renal proximal tubules from $\mathrm{NEMO}^{\mathrm{f} / \mathrm{fl}} \mathrm{PEPCK}-\mathrm{Cre}$ mice had a greater than $99 \%$ reduction in NEMO mRNA and a greater than $96 \%$ reduction in NEMO protein expression compared with $\mathrm{NEMO}^{\mathrm{f} /}$ ${ }^{\mathrm{fl}}$ mice. Therefore, $\mathrm{NEMO}^{\mathrm{f} / \mathrm{fl}} \mathrm{PEPCK}-\mathrm{Cre}$ mice showed near-complete deletion of renal PT NEMO and partial reduction in liver NEMO. This is consistent with how PEPCK-Cre mice were generated. The PEPCK-Cre transgene was generated using a mutated version of the PEPCK promoter, which reduces PEPCK expression in the liver by $60 \%$ and increases PEPCK expression in the kidney by 10 -fold in transgenic mice (17). We do not believe that partial reduction in hepatic NEMO contributed to attenuated ischemic AKI observed in $\mathrm{NEMO}^{\mathrm{fl} / \mathrm{fl}} \mathrm{PEPCK}-\mathrm{Cre}$ mice because ablation of hepatic NEMO potentiates hepatotoxicity and spontaneously induces liver inflammation, steatosis, and fibrosis $(24,43)$. Further supporting this, we demonstrated that WT and PT NEMO-deficient mice developed a similar degree of liver injury after renal IR. Therefore, we conclude that renal PT NEMO deletion or inhibition protects against ischemic AKI independent of hepatic NEMO.

Our previous and current study demonstrated kidney-selective delivery of NBP MNP of 27-94fold more than other organs, including the spleen (37). Moreover, we showed renal proximal tubular delivery of MNP with PEG/PHA lectin costaining (Figure 1C). PEG staining did not occur in extrarenal organs. Therefore, it is most likely that the reduction in inflammation and attenuation of kidneyinfiltrating proinflammatory cells was due to reduced ischemic AKI and decreased proinflammatory response. However, we cannot completely rule out the impact of NBP MNP (no matter how minor) on extrarenal inflammatory cells. 


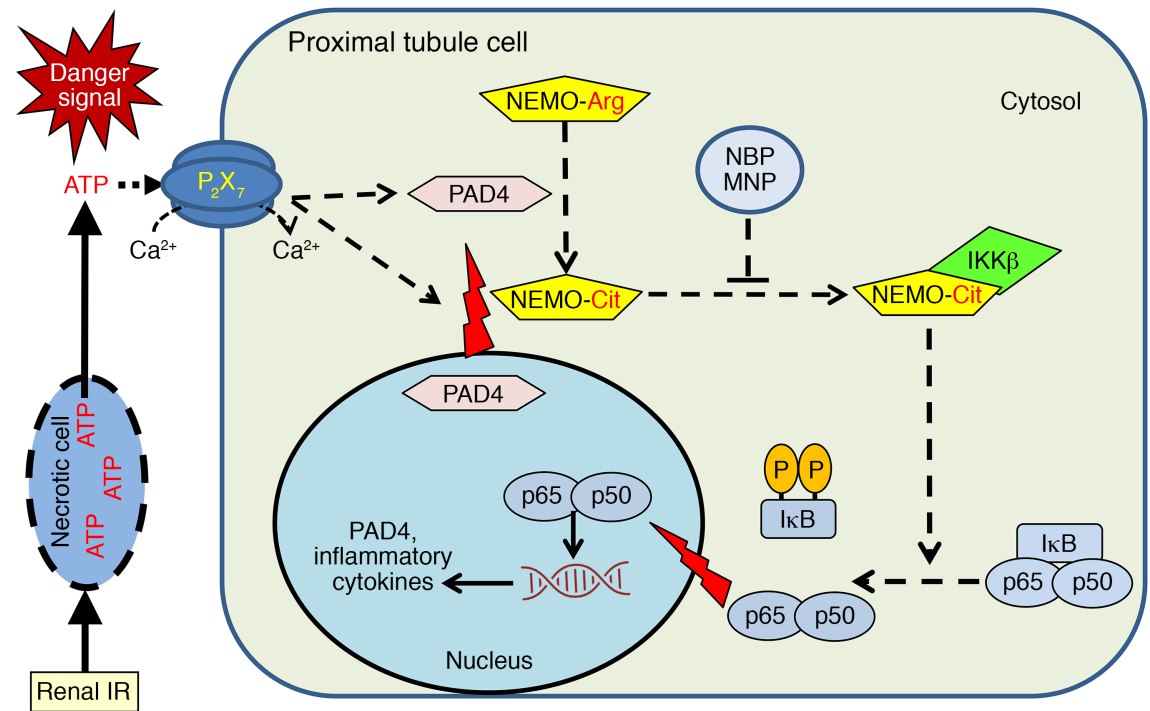

Figure 15. Overview of NEMO-mediated renal tubular inflammation and injury. ATP released by necrotic or dying renal cells activates P2X7 purinergic receptors to induce renal tubular PAD4. Cytosolic translocation of PAD4 after renal IR preferentially citrullinates NEMO, which in turn drives proinflammatory NF- $\mathrm{KB}$ signaling with increased cytokine/ chemokine synthesis and neutrophil infiltration. NEMO inhibition with MNP-encapsulated NBP protects against ischemic AKI and decreases renal tubular proinflammatory cytokine induction.

In summary, we demonstrated in this study that renal PT NEMO plays a critical role in ischemic AKI by promoting kidney tubular necrosis, inflammation, and apoptosis. We also demonstrated in this study a potentially novel and innovative method to treat ischemic AKI using NBP MNP. Our study suggests that kidney-targeted MNP-mediated selective drug delivery is an exciting method to treat AKI with improved therapeutic specificity and potentially reduced systemic toxicity by allowing a lower drug dosage. Our previous and current findings allow us to propose a summary of PAD4-mediated renal tubular inflammation and exacerbation of ischemic AKI (Figure 15). We showed that ATP released by necrotic or dying renal cells activated P2X7 purinergic receptors to induce renal tubular PAD4. Cytosolic translocation of PAD4 after renal IR preferentially citrullinated NEMO, which in turn drove proinflammatory NF- $\mathrm{B}$ signaling with increased cytokine/chemokine synthesis and neutrophil infiltration. NEMO inhibition with NBP MNP protected against ischemic AKI and decreased renal tubular proinflammatory cytokine induction.

\section{Methods}

Generation of mice with renal proximal tubule cell-specific NEMO deficiency. We bred mice with loxP-flanked Nemo alleles (NEMO ${ }^{\mathrm{fl} / \mathrm{fl}}$ mice; ref. 44) with mice that expressed Cre recombinase selectively in proximal tubular epithelia (Cre recombinase under the control of PEPCK-Cre - generated by Volker Haase, Vanderbilt University, Nashville, Tennessee, USA; ref. 17). All mice were backcrossed with C57BL/6 mice for at least 6 generations. This approach allowed us to generate sibling mice with proximal tubule-specific deletion of NEMO $\left(\mathrm{NEMO}^{\mathrm{f} / \mathrm{fl}}\right.$ PEPCK-Cre mice) or $\mathrm{WT}\left(\mathrm{NEMO}^{\mathrm{f} / \mathrm{fl}}\right)$ mice. Tail PCR with PEPCK-Cre and NEMO loxP-specific primers (Table 1) confirmed the genotypes of proximal tubule cell-specific NEMOnull mice and the control WT mice $\left(\mathrm{NEMO}^{\mathrm{fl} / \mathrm{fl}}\right)$ generated from breeding.

Confirmation of renal PT NEMO deletion in NEMO ${ }^{\text {Ilfl }}$ PEPCK-Cre mice. We confirmed selective deletion of renal PT NEMO in NEMO ${ }^{\mathrm{f} / \mathrm{fl}}$ PEPCK-Cre mice by measuring NEMO mRNA with RT-PCR and NEMO protein expression with immunoblotting using anti-NEMO antibody (ab178872, Abcam) in isolated proximal tubule cells (45) as described previously $(46,47)$. We also measured NEMO mRNA in bone marrow-derived macrophages and the kidney, spleen, liver, and small intestine. Primer design was based on published GenBank sequences (Table 1). To control for RNA loading, GAPDH mRNA expression was also measured.

Generation of MNPs and incorporation of NBP. MNPs encapsulating NBP (MilliporeSigma, 480025) were formulated similarly to previously described methods with minor modifications $(37,38)$. Briefly, $38-54 \mathrm{kDa}$ molecular weight PLGA (MilliporeSigma) was conjugated to $5 \mathrm{kDa}$ carboxylic acid-terminated PEG (Nanocs) 
Table 1. Primers used for genotyping

\begin{tabular}{|c|c|c|}
\hline Primers & Sequence (sense/antisense) & Annealing temp $\left({ }^{\circ} \mathrm{C}\right)$ \\
\hline \multirow{2}{*}{ NEMO FLOX } & 5'-ATGTGCCCAAGAACCATCCAG-3' & \multirow{2}{*}{$60^{\circ}$} \\
\hline & 5'-ATCACCTCTCСAAATCACCAG-3' & \\
\hline \multirow{2}{*}{ PEPCK-Cre } & 5'-TGGGCGGCATGGTGCAAGTT-3' & \multirow{2}{*}{$61^{\circ}$} \\
\hline & 5'-CGGTGCTAACCAGCGTTTTC-3' & \\
\hline
\end{tabular}

Primers used in genotyping to amplify mouse genomic DNA based on published GenBank sequences for mouse DNA. Annealing temperatures used for each primer are also provided.

before particle formulation. The conjugated copolymer $(100 \mathrm{mg}$ ) was dissolved in $2 \mathrm{~mL}$ acetonitrile. Then, 100 $\mu \mathrm{g}$ of NBP in water was added to the copolymer solution and bath sonicated for 2 minutes. The resultant emulsion was added dropwise to a solution of purified water $(4 \mathrm{~mL})$ and Pluronic F-68 (75 $\mu \mathrm{L}$; Thermo Fisher Scientific). After 2 hours of stirring, the particle solution was centrifuged at $5400 g$ for 15 minutes. The nanoparticle pellet was washed with $10 \mathrm{~mL}$ purified water and centrifuged under the same specifications. The resultant pellet was resuspended in a $2 \%$ sucrose solution and lyophilized for storage at $-20^{\circ} \mathrm{C}$. Empty control MNPs were formulated identically to NBP MNP as above without emulsion with the peptide.

The hydrodynamic diameter and PDI of the MNPs was characterized via dynamic light scattering (Malvern) in a $10 \mathrm{mg} / \mathrm{mL}$ PBS suspension. To quantify peptide loading into the particles, approximately 10 mg lyophilized particle powder was dissolved in $200 \mu \mathrm{L}$ acetonitrile and shaken at room temperature for 30 minutes. To this solution, we added $300 \mu \mathrm{L}$ Tris-EDTA buffer (Thermo Fisher Scientific) before centrifugation at $31,000 \mathrm{~g}$ for 30 minutes. The supernatant containing liberated peptide was used for quantification via the MicroBCA Assay Kit (Thermo Fisher Scientific) according to the manufacturer's instructions.

PEG IHC to test renal proximal tubular delivery of MNPs. Because the surface of MNPs is composed of PEG, we performed florescent IHC for PEG to detect renal proximal tubular localization of MNPs administered. Kidneys from mice treated with $38 \mathrm{mg} / \mathrm{kg}$ NBP MNP 6 hours before renal IR injury were fixed with $4 \%$ paraformaldehyde, dehydrated with $30 \%$ sucrose, frozen in OCT (Tissue-Tek), and cryosectioned (5 $\mu \mathrm{m})$. Kidney sections were permeabilized with $0.2 \%$ Triton X-100 for 10 minutes and the sections were then autoclaved in $10 \mathrm{mM}$ sodium citrate, $\mathrm{pH}$ 6.0, for 10 minutes to retrieve antigens. After blocking sections with PBS containing 10\% normal rabbit serum, sections were incubated with 1:100 anti-PEG antibody (ab94764, Abcam) specific to the PEG backbone plus PHA lectin antibody (proximal tubule-specific marker, Molecular Probes) or plus aquaporin-2 antibody (collecting duct-specific marker, AQP-002, Alomone Labs). After incubating sections with specific fluorescent secondary antibodies (Thermo Fisher Scientific), kidney slides were counterstained with DAPI to visualize cell nuclei, mounted with Vectashield (Vector) mounting media, and imaged with a fluorescent microscope (Olympus IX81). We also performed PEG florescent IHC in the lung, spleen, and liver.

Renal IR injury in mice. After Columbia University IACUC approval, 8-10-week-old male PT NEMOdeficient $\left(\mathrm{NEMO}^{\mathrm{f} / \mathrm{fl}}\right.$ PEPCK-Cre) mice, control WT $\left(\mathrm{NEMO}^{\mathrm{f} / \mathrm{fl}}\right)$ mice, or C57BL/6 mice (The Jackson Laboratory) weighing 20-25 g were anesthetized with i.p. pentobarbital (MilliporeSigma: $50 \mathrm{mg} / \mathrm{kg}$ body weight or to effect). Mice were then subjected to right nephrectomy and 30 minutes of left renal ischemia as described previously $(48,49)$. C57BL/6 mice received i.v. NBP MNPs (19 or $38 \mathrm{mg} / \mathrm{kg}$ ) or empty MNPs 6 hours before renal ischemia or 15 minutes after reperfusion based on previous studies (37, 39). Previous studies showed that the dosing ranges of approximately $25-50 \mathrm{mg} / \mathrm{kg}$ MNP had the greatest accumulation/ kidney selectivity profile for the nanoparticles ( 27-94-fold kidney selectivity over other organs) (37). We previously showed that exogenous PAD4 exacerbates renal IR injury (12). To test whether exogenous PAD4 targets renal PT NEMO to exacerbate ischemic AKI, PT NEMO-deficient or control $\left(\mathrm{NEMO}^{\mathrm{f} / \mathrm{fl}}\right)$ mice were pretreated with human rPAD4 (10 $\mu$ g, i.v., Cayman Chemical) 15 minutes before 20 minutes of renal IR injury. To determine whether recombinant rPAD4 enters kidney and renal proximal tubular cells, human PAD4 protein expressions in both whole kidney and primary cultures of proximal tubules of mice were measured by Western blotting using anti-human PAD4 antibody (ab128086, Abcam) 4 hours after rPAD4 treatment. Sham-operated animals underwent anesthesia followed by laparotomy, right nephrectomy, bowel manipulations, and wound closure without renal ischemia. Body temperatures of all mice were sustained at approximately $37^{\circ} \mathrm{C}$ using a surgical heating pad during surgery and during recovery from anesthesia. 
Table 2. Primers used for quantitative reverse transcription polymerase chain reactions

\begin{tabular}{|c|c|c|}
\hline Primers & Sequence (sense/antisense) & Annealing temp $\left({ }^{\circ} \mathrm{C}\right)$ \\
\hline \multirow{2}{*}{ mouse TNF- $\alpha$} & 5'-TACTCAACTTCGGGGTCATTCGTCC-3' & \multirow{2}{*}{$65^{\circ}$} \\
\hline & 5'-CAGCCTTCTCCCTTCAAGAGAACC-3' & \\
\hline \multirow{2}{*}{ mouse MCP-1 } & 5'-ACCTCСTGCTACTCATTCAC-3' & \multirow{2}{*}{$60^{\circ}$} \\
\hline & 5'-TTGAGGTGGTTGTGGAAAAG-3' & \\
\hline \multirow{2}{*}{ mouse MIP-2 } & 5'-CCAAGGGTTCACTTCAAGAAC-3' & \multirow{2}{*}{$60^{\circ}$} \\
\hline & 5'-AGCGAGGCACATCAGGTACG-3' & \\
\hline \multirow{2}{*}{ mouse KC } & 5'-CAATGAGCTGCGCTGTCAGTG-3' & \multirow{2}{*}{$60^{\circ}$} \\
\hline & 5'-CTTGGGGACACCTTTTAGCATC-3' & \\
\hline \multirow{2}{*}{ mouse IL-6 } & 5'-CCGGAGAGGAGACTTCACAG-3' & \multirow{2}{*}{$62^{\circ}$} \\
\hline & 5'-GGAAATTGGGGTAGGAAGGA-3' & \\
\hline \multirow{2}{*}{ mouse ICAM-1 } & 5'-TGTTTCCTCСCTCTGAAGC-3' & \multirow{2}{*}{$60^{\circ}$} \\
\hline & 5'-CTTCGTTTGTGATCCTCCG-3' & \\
\hline \multirow{2}{*}{ mouse NGAL } & 5'-CACCACGGACTACAACCACTTCGC-3' & \multirow{2}{*}{$66^{\circ}$} \\
\hline & 5'-TCAGTTGTCAATGCATTGGTCGGTG-3' & \\
\hline \multirow{2}{*}{ mouse NEMO } & 5'-TGCCTTCAGAGCAGGGTACT-3' & \multirow{2}{*}{$66^{\circ}$} \\
\hline & 5'-CAGTCTCTCCACCAGСTTCC-3' & \\
\hline \multirow{2}{*}{ human MCP-1 } & 5'-AGCAAGTGTCCCAAAGAAGC-3' & \multirow{2}{*}{$64^{\circ}$} \\
\hline & 5'-CTCAAAACATCCCACGGGTA-3' & \\
\hline \multirow{2}{*}{ human MIP-2 } & 5'-CTTCCCACСTCTCCTCCTC-3' & \multirow{2}{*}{$64^{\circ}$} \\
\hline & 5'-GCTTTCTGCCCATTCTTCAG-3' & \\
\hline \multirow{2}{*}{ human IL-8 } & 5'-TCTGCAGCTCTGTGTCAAGG-3' & \multirow{2}{*}{$64^{\circ}$} \\
\hline & 5'-ATTGCATCTGGCAACCCTAC-3' & \\
\hline \multirow{2}{*}{ human IL-6 } & 5'-AAAGAGGCACTGGCAGAAAA-3' & \multirow{2}{*}{$64^{\circ}$} \\
\hline & 5'-CATGCTACATTTGCCGAAGA-3' & \\
\hline \multirow{2}{*}{ human TNF- $\alpha$} & 5'-CGGGACGTGGAGCTGGCCGAGGAG-3' & \multirow{2}{*}{$68^{\circ}$} \\
\hline & 5'-CACCAGCTGGTTATCTCTCAGCTC-3' & \\
\hline \multirow{2}{*}{ human ICAM-1 } & 5'-GCAGACAGTGACCATCTACAGC-3' & \multirow{2}{*}{$60^{\circ}$} \\
\hline & 5'-GCCATCCTTTAGACACTTCAGC-3' & \\
\hline \multirow{2}{*}{ GAPDH } & 5'-ACCACAGTCCATCCCATCAC-3' & \multirow{2}{*}{$65^{\circ}$} \\
\hline & 5'-CACCACCCTGTTGCTGTAGCC-3' & \\
\hline
\end{tabular}

Primers used in quantitative reverse transcription polymerase chain reactions to amplify mouse or human cDNA based on published GenBank sequences. Annealing temperatures used for each primer are also provided.

For pain management, all mice received $0.1-1 \mathrm{mg} / \mathrm{kg}$ s.c. sustained-release buprenorphine before surgery. Plasma and kidneys were collected 24 hours after renal IR injury to examine renal dysfunction (plasma creatinine, BUN, and histology); inflammation (neutrophil infiltration, cytokine mRNAs); and apoptosis (TUNEL staining).

Detection of renal injury and hepatic injury after renal IR. Twenty-four hours after renal IR injury or sham surgery, we measured plasma BUN, creatinine, and ALT using an enzymatic reagent kit (Thermo Fisher Scientific). This method of plasma creatinine assay limits the interferences from mouse plasma chromogens known to occur in the Jaffe method. We also performed qRT-PCR for kidney NGAL mRNA from mice subjected to sham surgery or to renal IR injury. NGAL is an early and sensitive marker of renal tubular injury (50).

Histological detection of kidney and liver injury. Twenty-four hours after renal IR injury or sham surgery, kidney $H \& E$ sections were assessed using a grading scale of kidney necrotic IR injury to the proximal tubules ( $0-4$, Renal Injury Score) as outlined by Jablonski et al. (51). The renal pathologist was blinded to the experimental conditions. Deidentified slides were H\&E-stained coronal cross sections of bivalved whole kidney showing full-thickness cortex and medulla. The cortical and medullary parenchyma was evaluated in its entirety in all the microscopic fields covering the entire slide to generate the Jablonski score. We also examined liver H\&E sections for differences in hepatic histological injury between WT mice and renal PT NEMO-deficient mice.

Detection of kidney apoptosis. Twenty-four hours after sham surgery or renal IR injury, TUNEL staining detected fragmented DNA as described (52) using a commercially available kit (Roche). 
Apoptotic TUNEL-positive cells were quantified in 5-7 randomly chosen $\times 200$ original magnification microscope image fields in the corticomedullary junction, and results were expressed as apoptotic cells counted per field.

Detection of kidney neutrophil infiltration. Kidney neutrophil infiltration after IR injury or sham surgery was detected with IHC staining using rat anti-mouse Ly6G monoclonal antibody (14-5931-85, Thermo Fisher Scientific) as described $(46,53)$. Primary $\operatorname{IgG}_{2 \mathrm{a}}$ antibody (MCA1212, AbD Serotec) was used as a negative isotype control. Quantification of kidney-infiltrating neutrophils was performed using 5-7 randomly chosen $\times 200$ original magnification microscope image fields (corticomedullary junction for kidney neutrophils), and results were expressed as neutrophils counted per field.

IHC staining for $N F-\kappa B$ and $p-N F-\kappa B$. We detected $N F-\kappa B$ and $\mathrm{p}-\mathrm{NF}-\kappa \mathrm{B}$ expression after IR inju-

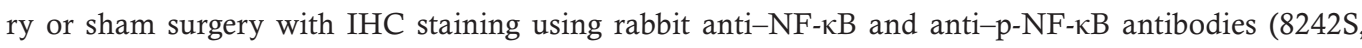

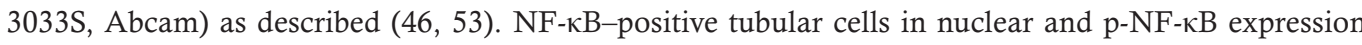
were quantified from 3 to 5 randomly chosen $\times 200$ original magnification microscope image fields as described by Ruifrok et al. (54).

$q R T-P C R$ for proinflammatory cytokine and chemokine $m R N A$ expression. Renal inflammation after IR was also assessed by measuring proinflammatory mRNA markers, including IL-6, ICAM-1, MCP-1, KC, MIP-2, and TNF- $\alpha$ qRT-PCR, as described previously with primers listed in Table 2 (46). Primer design was based on published GenBank sequences. To confirm equal RNA input, GAPDH mRNA and relative expression of proinflammatory mRNA were calculated with the $\Delta \Delta$ Ct method. qRT-PCR was performed using MyiQ Real Time Detection System (Bio-Rad) using FastStart Universal SYBR Green Master (ROX) (Roche).

ELISA for MCP-1 and MIP-2. Plasma MCP-1 and MIP-2 levels were measured with mouse-specific ELISA kits 24 hours after sham or renal IR surgery (Thermo Fisher Scientific).

Cell culture and in vitro experiments. Mouse kidney proximal tubules from control $\left(\mathrm{NEMO}^{\mathrm{f} / \mathrm{fl}}\right)$ or PT NEMO-null mice were isolated using Percoll density gradient separation and grown as described previously (45). Bone marrow-derived macrophages were isolated from $\mathrm{NEMO}^{\mathrm{f} / \mathrm{fl}}$ or PT NEMO-null mice as previously described (55). Mouse hind limb femurs and tibiae were dissected, and marrow plugs were dispersed by passing a 26-gauge needle through them, and the cells were suspended by vigorous pipetting and washed. Cells were cultured in DMEM/F12 medium supplemented with $100 \mathrm{IU} / \mathrm{mL}$ penicillin, $100 \mu \mathrm{g} /$ $\mathrm{mL}$ streptomycin, $10 \% \mathrm{FBS}$, and $10 \mathrm{ng} / \mathrm{mL} \mathrm{M}-\mathrm{CSF}$ at $37^{\circ} \mathrm{C}$ in a humidified $5 \% \mathrm{CO}_{2}$ atmosphere.

Mouse kidney proximal tubule cells isolated from $\mathrm{NEMO}^{\mathrm{f} / \mathrm{fl}}$ or PT NEMO-null mice were treated with human $\mathrm{rPAD} 4(10 \mu \mathrm{g} / \mathrm{mL}$ for 6 hours) or with recombinant murine TNF- $\alpha(10 \mathrm{ng} / \mathrm{mL}$ for 6 hours) or with LPS (10 $\mu \mathrm{g} / \mathrm{mL}$ for 6 hours) when confluent and proinflammatory cytokine induction were measured (TNF- $\alpha, \mathrm{MCP}-1$, and MIP-2). Bone marrow-derived macrophages isolated from $\mathrm{NEMO}^{\mathrm{f} / \mathrm{fl}}$ or PT NEMO-null mice were treated with human $\mathrm{rPAD} 4(10 \mu \mathrm{g} / \mathrm{mL}$ for 6 hours) to determine induction of proinflammatory cytokines. We also performed p65 subunit of NF- $\mathrm{BB}$ immunoblotting in mouse renal proximal tubule cells treated with vehicle (saline) or with human rPAD4 (time and dose) as described $(46,56)$. Mouse proximal tubular cell nuclear fractions were prepared and subjected to immunoblotting with p65 subunit of NF- $\mathrm{kB}$ antibody from Santa Cruz Biotechnology (sc-8008) as described (13). All blots were imaged using ECL detection reagent (Thermo Fisher Scientific) and exposure using UVP Auto Chemi Darkroom and Vision Works LS acquisition and analysis software (Vision Works LS)

Statistics. Data were analyzed with 2-tailed Student's $t$ test, 1-way ANOVA plus Tukey's post hoc multiple-comparisons test, or Mann-Whitney nonparametric $U$ test to analyze renal injury scores. All data are expressed throughout the text as means \pm SEM. $P$ values of less than 0.05 were considered significant.

Study approval. All animal care and experimental procedures were performed under a study protocol approved by Columbia University's IACUC.

\section{Author contributions}

SJH and HTL conceived and designed research; SJH and MK performed experiments; SJH, MK, VD, and HTL analyzed data; SJH and HTL interpreted the results of experiments; SJH and HTL prepared figures; SJH and HTL drafted the manuscript; RMW, MK, and MSS provided material and mice; SJH, RMW, DAH, MSS, and HTL edited and revised the manuscript; and SJH, RMW, MK, DAH, VD, MSS, and HTL approved the final version of the manuscript. 


\section{Acknowledgments}

HTL was supported in part by the Department of Anesthesiology at Columbia University and by the National Institute of Diabetes and Digestive and Kidney Diseases (DK-109544 and DK-115694). RMW was supported by the American Heart Association Postdoctoral Fellowship (17POST33650043) and the City College of New York Grove School of Engineering. DAH was supported by R01-DK114321.

Address correspondence to: H. Thomas Lee, Department of Anesthesiology, Anesthesiology Research Laboratories, Columbia University, P\&S Box 46 (PH-5), 630 West 168th Street, New York, New York 10032-3784, USA. Phone: 212.305.1807; Email: t1128@columbia.edu.

1. Kork F, et al. Minor postoperative increases of creatinine are associated with higher mortality and longer hospital length of stay in surgical patients. Anesthesiology. 2015;123(6):1301-1311.

2. Hilmi IA, et al. Acute kidney injury following orthotopic liver transplantation: incidence, risk factors, and effects on patient and graft outcomes. Br J Anaesth. 2015;114(6):919-926.

3. Chertow GM, Burdick E, Honour M, Bonventre JV, Bates DW. Acute kidney injury, mortality, length of stay, and costs in hospitalized patients. J Am Soc Nephrol. 2005;16(11):3365-3370.

4. Jones DR, Lee HT. Perioperative renal protection. Best Pract Res Clin Anaesthesiol. 2008;22(1):193-208.

5. Aronson S, Blumenthal R. Perioperative renal dysfunction and cardiovascular anesthesia: concerns and controversies. $J$ Cardiothorac Vasc Anesth. 1998;12(5):567-586.

6. Yap SC, Lee HT. Adenosine and protection from acute kidney injury. Curr Opin Nephrol Hypertens. 2012;21(1):24-32.

7. Pefanis A, Ierino FL, Murphy JM, Cowan PJ. Regulated necrosis in kidney ischemia-reperfusion injury. Kidney Int. 2019;96(2):291-301.

8. Zheng L, Gao W, Hu C, Yang C, Rong R. Immune cells in ischemic acute kidney injury. Curr Protein Pept Sci. 2019;20(8):770-776.

9. Jang HR, Rabb H. Immune cells in experimental acute kidney injury. Nat Rev Nephrol. 2015;11(2):88-101.

10. Kinsey GR, Okusa MD. Expanding role of T cells in acute kidney injury. Curr Opin Nephrol Hypertens. 2014;23(1):9-16.

11. Kusch A, et al. Novel signalling mechanisms and targets in renal ischaemia and reperfusion injury. Acta Physiol (Oxf). 2013;208(1):25-40.

12. Rabadi M, Kim M, D’Agati V, Lee HT. Peptidyl arginine deiminase-4-deficient mice are protected against kidney and liver injury after renal ischemia and reperfusion. Am J Physiol Renal Physiol. 2016;311(2):F437-F449.

13. Ham A, et al. Peptidyl arginine deiminase-4 activation exacerbates kidney ischemia-reperfusion injury. Am J Physiol Renal Physiol. 2014;307(9):F1052-F1062.

14. Rabadi M, et al. ATP induces PAD4 in renal proximal tubule cells via P2X7 receptor activation to exacerbate ischemic AKI Am J Physiol Renal Physiol. 2018;314(2):F293-F305.

15. Rabadi MM, Han SJ, Kim M, D’Agati V, Lee HT. Peptidyl arginine deiminase-4 exacerbates ischemic AKI by finding NEMO. Am J Physiol Renal Physiol. 2019;316(6):F1180-F1190.

16. Beale EG, Clouthier DE, Hammer RE. Cell-specific expression of cytosolic phosphoenolpyruvate carboxykinase in transgenic mice. FASEB J. 1992;6(15):3330-3337.

17. Rankin EB, Tomaszewski JE, Haase VH. Renal cyst development in mice with conditional inactivation of the von Hippel-Lindau tumor suppressor. Cancer Res. 2006;66(5):2576-2583.

18. Bhattacharyya S, Borthakur A, Dudeja PK, Tobacman JK. Lipopolysaccharide-induced activation of NF-kB non-canonical pathway requires BCL10 serine 138 and NIK phosphorylations. Exp Cell Res. 2010;316(19):3317-3327.

19. Mordmüller B, Krappmann D, Esen M, Wegener E, Scheidereit C. Lymphotoxin and lipopolysaccharide induce NF-kappaB-p52 generation by a co-translational mechanism. EMBO Rep. 2003;4(1):82-87.

20. Souvannavong V, Saidji N, Chaby R. Lipopolysaccharide from Salmonella enterica activates NF-kappaB through both classical and alternative pathways in primary B Lymphocytes. Infect Immun. 2007;75(10):4998-5003.

21. Guo L, Lee HH, Noriega ML, Paust HJ, Zahner G, Thaiss F. Lymphocyte-specific deletion of IKK2 or NEMO mediates an increase in intrarenal Th17 cells and accelerates renal damage in an ischemia-reperfusion injury mouse model. Am J Physiol Renal Physiol. 2016;311(5):F1005-F1014.

22. Swarnkar G, et al. Myeloid deletion of NEMO causes osteopetrosis in mice owing to upregulation of transcriptional repressors. Sci Rep. 2016;6:29896.

23. Reale C, et al. NF-kB essential modulator (NEMO) is critical for thyroid function. J Biol Chem. 2016;291(11):5765-5773.

24. Luedde T, et al. Deletion of NEMO/IKKgamma in liver parenchymal cells causes steatohepatitis and hepatocellular carcinoma. Cancer Cell. 2007;11(2):119-132.

25. Bajwa A, Kinsey GR, Okusa MD. Immune mechanisms and novel pharmacological therapies of acute kidney injury. Curr Drug Targets. 2009;10(12):1196-1204.

26. Akcay A, Nguyen Q, Edelstein CL. Mediators of inflammation in acute kidney injury. Mediators Inflamm. 2009;2009:137072.

27. Schröfelbauer B, Polley S, Behar M, Ghosh G, Hoffmann A. NEMO ensures signaling specificity of the pleiotropic IKK $\beta$ by directing its kinase activity toward IkBa. Mol Cell. 2012;47(1):111-121.

28. Strickland I, Ghosh S. Use of cell permeable NBD peptides for suppression of inflammation. Ann Rheum Dis. 2006;65(supp1 3):iii75-iii82.

29. Zhang Q, Lenardo MJ, Baltimore D. 30 years of NF-kB: a blossoming of relevance to human pathobiology. Cell. 2017;168(1-2):37-57.

30. Mitchell S, Vargas J, Hoffmann A. Signaling via the NF-kB system. Wiley Interdiscip Rev Syst Biol Med. 2016;8(3):227-241.

31. Sun B, Karin M. NF-kappaB signaling, liver disease and hepatoprotective agents. Oncogene. 2008;27(48):6228-6244.

32. Markó L, et al. Tubular epithelial NF-кB activity regulates ischemic AKI. J Am Soc Nephrol. 2016;27(9):2658-2669. 
33. Molitoris BA. Therapeutic translation in acute kidney injury: the epithelial/endothelial axis. J Clin Invest. 2014;124(6):2355-2363. 34. de Caestecker M, et al. Bridging translation by improving preclinical study design in AKI. J Am Soc Nephrol. 2015;26(12):2905-2916.

35. Jo SK, Rosner MH, Okusa MD. Pharmacologic treatment of acute kidney injury: why drugs haven't worked and what is on the horizon. Clin J Am Soc Nephrol. 2007;2(2):356-365.

36. Elapavaluru S, Kellum JA. Why do patients die of acute kidney injury? Acta Clin Belg. 2007;62(suppl 2):326-331.

37. Williams RM, et al. Selective nanoparticle targeting of the renal tubules. Hypertension. 2018;71(1):87-94.

38. Williams RM, et al. Mesoscale nanoparticles selectively target the renal proximal tubule epithelium. Nano Lett. 2015;15(4):2358-2364.

39. Han SJ, Williams RM, D'Agati V, Jaimes EA, Heller DA, Lee HT. Selective nanoparticle-mediated targeting of renal tubular Toll-like receptor 9 attenuates ischemic acute kidney injury. Kidney Int. 2020;98(1):76-87.

40. Han SJ, Li H, Kim M, Shlomchik MJ, Lee HT. Kidney proximal tubular TLR9 exacerbates ischemic acute kidney injury. J Immunol. 2018;201(3):1073-1085.

41. Yuan X, Lee JW, Bowser JL, Neudecker V, Sridhar S, Eltzschig HK. Targeting hypoxia signaling for perioperative organ injury. Anesth Analg. 2018;126(1):308-321.

42. Williams RM, Jaimes EA, Heller DA. Nanomedicines for kidney diseases. Kidney Int. 2016;90(4):740-745.

43. Ehlken H, et al. Death receptor-independent FADD signalling triggers hepatitis and hepatocellular carcinoma in mice with liver parenchymal cell-specific NEMO knockout. Cell Death Differ. 2014;21(11):1721-1732.

44. Schmidt-Supprian M, et al. NEMO/IKK gamma-deficient mice model incontinentia pigmenti. Mol Cell. 2000;5(6):981-992.

45. Vinay P, Gougoux A, Lemieux G. Isolation of a pure suspension of rat proximal tubules. Am J Physiol. 1981;241(4):F403-F411.

46. Park SW, et al. A1 adenosine receptor allosteric enhancer PD-81723 protects against renal ischemia-reperfusion injury. Am $J$ Physiol Renal Physiol. 2012;303(5):F721-F732.

47. Park SW, Kim M, Brown KM, D’Agati VD, Lee HT. Inhibition of sphingosine 1-phosphate receptor 2 protects against renal ischemia-reperfusion injury. J Am Soc Nephrol. 2012;23(2):266-280.

48. Kim M, et al. Selective renal overexpression of human heat shock protein 27 reduces renal ischemia-reperfusion injury in mice. Am J Physiol Renal Physiol. 2010;299(2):F347-F358.

49. Lee HT, et al. Interleukin-11 protects against renal ischemia and reperfusion injury. Am J Physiol Renal Physiol. 2012;303(8):F1216-F1224.

50. Mishra J, et al. Identification of neutrophil gelatinase-associated lipocalin as a novel early urinary biomarker for ischemic renal injury. J Am Soc Nephrol. 2003;14(10):2534-2543.

51. Jablonski P, Howden BO, Rae DA, Birrell CS, Marshall VC, Tange J. An experimental model for assessment of renal recovery from warm ischemia. Transplantation. 1983;35(3):198-204.

52. Park SW, Chen SW, Kim M, D'Agati VD, Lee HT. Human heat shock protein 27-overexpressing mice are protected against acute kidney injury after hepatic ischemia and reperfusion. Am J Physiol Renal Physiol. 2009;297(4):F885-F894.

53. Park SW, Kim M, Kim M, D'Agati VD, Lee HT. Sphingosine kinase 1 protects against renal ischemia-reperfusion injury in mice by sphingosine-1-phosphate1 receptor activation. Kidney Int. 2011;80(12):1315-1327.

54. Ruifrok AC, Johnston DA. Quantification of histochemical staining by color deconvolution. Anal Quant Cytol Histol. 2001;23(4):291-299

55. Zhang X, Goncalves R, Mosser DM. The isolation and characterization of murine macrophages. Curr Protoc Immunol. 2008; Chapter 14:Unit 14.1.

56. Park SW, et al. Proximal tubule sphingosine kinase-1 has a critical role in A1 adenosine receptor-mediated renal protection from ischemia. Kidney Int. 2012;82(8):878-891. 